Linköping Studies in Science and Technology.

Dissertations No. 1663

\title{
On Some Combinatorial Optimization Problems
}

Algorithms and Complexity

\author{
Hannes Uppman
}

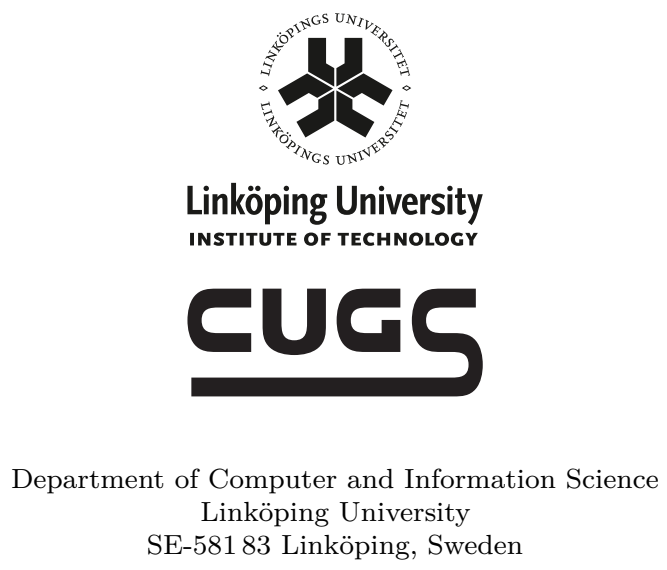

Linköping 2015 
Copyright (c) 2015 Hannes Uppman, unless otherwise noted

ISBN 978-91-7519-072-3

ISSN 0345-7524

Printed by LiU-Tryck, Linköping, Sweden, 2015 


\section{Abstract}

This thesis is about the computational complexity of several classes of combinatorial optimization problems, all related to the constraint satisfaction problems.

A constraint language consists of a domain and a set of relations on the domain. For each such language there is a constraint satisfaction problem (CSP). In this problem we are given a set of variables and a collection of constraints, each of which is constraining some variables with a relation in the language. The goal is to determine if domain values can be assigned to the variables in a way that satisfies all constraints. An important question is for which constraint languages the corresponding CSP can be solved in polynomial time. We study this kind of question for optimization problems related to the CSPs.

The main focus is on extended minimum cost homomorphism problems. These are optimization versions of CSPs where instances come with an objective function given by a weighted sum of unary cost functions, and where the goal is not only to determine if a solution exists, but to find one of minimum cost. We prove a complete classification of the complexity for these problems on three-element domains. We also obtain a classification for the so-called conservative case.

Another class of combinatorial optimization problems are the surjective maximum CSPs. These problems are variants of CSPs where a non-negative weight is attached to each constraint, and the objective is to find a surjective mapping of the variables to values that maximizes the weighted sum of satisfied constraints. The surjectivity requirement causes these problems to behave quite different from for example the minimum cost homomorphism problems, and many powerful techniques are not applicable. We prove a dichotomy for the complexity of the problems in this class on two-element domains. An essential ingredient in the proof is an algorithm that solves a generalized version of the minimum cut problem. This algorithm might be of independent interest.

In a final part we study properties of NP-hard optimization problems. This is done with the aid of restricted forms of polynomial-time reductions that for example preserves solvability in sub-exponential time. Two classes of 
optimization problems similar to those discussed above are considered, and for both we obtain what may be called an easiest NP-hard problem. We also establish some connections to the exponential time hypothesis.

This work has been supported in part by the National Graduate School in Computer Science (CUGS), Sweden. 


\section{Populärvetenskaplig sammanfattning}

Optimering går ut på att hitta värden för ett antal variabler så att resultatet blir så bra som möjligt (enligt en given kostnadsfunktion). Vi studerar kombinatoriska optimeringsproblem, problem där man för varje variabel enbart har ett ändligt antal möjliga val. Sådana problem är i någon mening lätta; för att hitta en så bra lösning som möjligt kan man helt enkelt prova alla sätt att välja värden för variablerna. Tyvärr är det här inte någon metod som fungerar i praktiken, redan vid ett fåtal variabler kan mängden alternativ bli så stor att den omöjligen kan gås igenom.

Huvuddelen av avhandlingen handlar om för vilka optimeringsproblem det finns en effektiv algoritm, och för vilka det är mycket osannolikt att en sådan algoritm existerar. En mer exakt formulering av frågan vi ställer oss är: Vilka problem har en polynomisk algoritm och vilka problem är NP-svåra? Problem för vilka det finns en polynomisk algoritm kan i någon mening ses som effektivt lösbara. NP-svåra problem tros däremot inte kunna lösas effektivt. Att visa att inget NP-svårt problem har en polynomisk algoritm (eller att det mot förmodan faktiskt finns en sån algoritm) är ett välkänt öppet problem känt som $\mathrm{P}$ mot NP frågan, och tros vara mycket svårt. Till exempel har Clay Mathematics Institute utlyst en belöning på en miljon dollar för en lösning.

Istället för att studera enskilda problem undersöker vi stora familjer, familjer som innehåller många viktiga problem med åtskilliga teoretiska och praktiska tillämpningar och som tidigare studerats enskilt. Syftet med det här angreppssättet är att avslöja fundamentala egenskaper som antingen möjliggör eller omöjliggör effektiva algoritmer. Fokus ligger alltså inte på att hitta den snabbaste algoritmen för ett enskilt problem, utan på att hitta enkla förklaringar till varför en stor klass av problem är NP-svåra, eller egenskaper som omvänt kan utnyttjas och därigenom möjliggöra en effektiv algoritm.

Främst studerar vi så kallade "minimum cost homomorphism problems" och "minimum solution problems" som båda är klasser av kombinatoriska optimeringsproblem. Vi beskriver bland annat exakt vilka sådana problem som är NP-svåra och vilka som är polynomiska när man för varje variabel har tre 
värden att välja på. En annan familj av optimeringsproblem vi studerar är "surjective maximum constraint satisfaction problems". För den här klassen ger vi en fullständig klassificering då man har två värden (till exempel "sant" och "falskt"). De effektivt lösbara problemen visar sig här komma i två sorter. Välkända metoder löser problemen av den ena sorten, och för att hantera problemen av den andra konstruerar vi en egen metod som löser en generalisering av minsta-snitt problemet. Den här algoritmen kan eventuellt vara användbar också i andra sammanhang. Slutligen studerar vi egenskaper hos NP-svåra optimeringsproblem och kan bland annat för två problemklasser hitta vad som kan kallas klassens lättaste NP-svåra problem. 


\section{Acknowledgments}

I have received support from many, for that I am very grateful.

First of all I want to thank my supervisor Peter Jonsson for his encouragement, guidance and patience, and my secondary supervisors Christer Bäckström and Ulf Nilsson for all their help.

Thanks also to my co-authors Peter Jonsson, Victor Lagerkvist and Johannes Schmidt, and to my colleagues at TCSLAB, especially Tomas Lööw and Michał Wrona who on separate occasions have traveled with me across the Atlantic.

Many teachers have done their best to educate me, thank you! I especially want to thank Leif Melkersson for his extensive feedback.

Finally, I want to thank my family and friends, and Thao, for all their support and encouragement.

Linköping, April 2015 
viii 


\section{List of papers}

1 Hannes Uppman, Max-Sur-CSP on Two Elements, in Principles and Practice of Constraint Programming: 18th International Conference (CP 2012) (Michela Milano, ed.), Lecture Notes in Computer Science (LNCS), vol. 7514, 2013, pp. 38-54, doi 10.1007/978-3-642-33558-7_6

2 Hannes Uppman, The Complexity of Three-Element Min-Sol and Conservative Min-Cost-Hom, in Automata, Languages, and Programming: 40th International Colloquium, (ICALP 2013) (Fedor V. Fomin, Rūsinš Freivalds, Marta Kwiatkowska, and David Peleg, eds.), Lecture Notes in Computer Science (LNCS), vol. 7965, 2013, pp. 804-815, doi 10.1007/9783-642-39206-1_68

3 Hannes Uppman, Computational Complexity of the Extended Minimum Cost Homomorphism Problem on Three-Element Domains, in 31st International Symposium on Theoretical Aspects of Computer Science, (STACS 2014) (Ernst W. Mayr and Natacha Portier, eds.), Leibniz International Proceedings in Informatics (LIPIcs), vol. 25, 2014, pp. 651-662, doi 10.4230/LIPIcs.STACS.2014.651

4 Peter Jonsson, Victor Lagerkvist, Johannes Schmidt, and Hannes Uppman, Relating the Time Complexity of Optimization Problems in Light of the Exponential-Time Hypothesis, in Mathematical Foundations of Computer Science 2014: 39th International Symposium, (MFCS 2014) (Erzsébet Csuhaj-Varjú, Martin Dietzfelbinger, and Zoltán Ésik, eds.), Lecture Notes in Computer Science (LNCS), vol. 8635, 2014, pp. 408-419, doi 10.1007/978-3-662-44465-8_35 


\section{Contents}

I Introduction 1

1 Complexity and constraint problems 3

1 Computational complexity . . . . . . . . . . . . . . 3

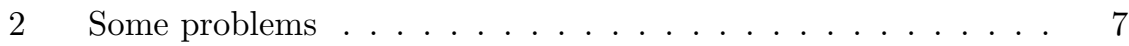

3 Constraint satisfaction problems . . . . . . . . . . . 10

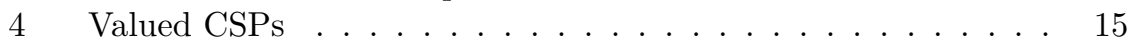

2 Contributions 21

1 Main contributions . . . . . . . . . . . . . . . . 21

2 A few open problems . . . . . . . . . . . . . . 23

\section{Papers 33}

$\begin{array}{ll}\text { Paper } 1 & 37\end{array}$

Max-Sur-CSP on Two Elements
$1 \quad$ Introduction $\ldots \ldots \ldots \ldots \ldots \ldots \ldots$

2 Complexity Dichotomy . . . . . . . . . . . . . . . . . 41

3 A Generalised Minimum Cut Problem . . . . . . . . . . . . . 49

4 Remarks and Open Ends . . . . . . . . . . . . . . . . 54

$\begin{array}{ll}\text { Paper } 2 & 61\end{array}$

Three-element Min-Sol and Conservative Min-Cost-Hom

1 Introduction . . . . . . . . . . . . . . . . . . 61

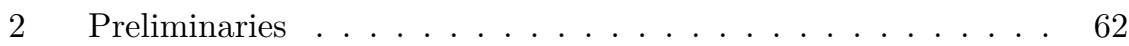

3 Contributions .................... 64

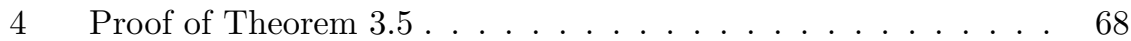

$5 \quad$ Proof of Proposition $3.8 \ldots \ldots \ldots \ldots$

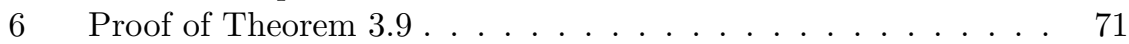

7 Concluding Remarks . . . . . . . . . . . . . . . . . . 72

A Proof of Theorem $3.10 \ldots \ldots \ldots \ldots \ldots$

B Proof of Lemma $3.11 \ldots \ldots \ldots$. . . . . . . . . . 82 
C Proof of Lemma $3.12 \ldots \ldots \ldots$. . . . . . . . . . 84

$\begin{array}{lr}\text { Paper } 3 & \mathbf{8 9}\end{array}$

Complexity of the Extended Min-Cost-Hom on Three-Element Domains

1 Introduction . . . . . . . . . . . . . . . . . 89

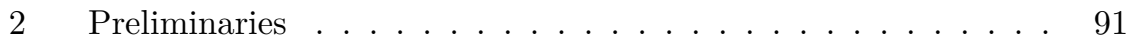

3 Tractable languages . . . . . . . . . . . . . . . . . 93

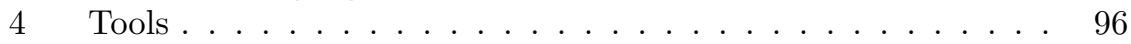

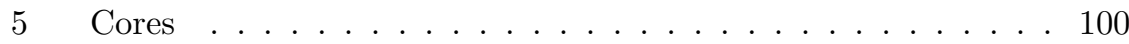

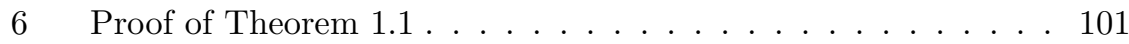

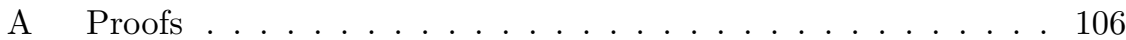

Paper 4

125

Relating the Time Complexity of Optimization Problems

1 Introduction . . . . . . . . . . . . . . . 125

2 Preliminaries ................... 127

3 The Easiest NP-Hard Max-Ones and VCSP Problems . . . . . 131

4 Subexponential Time and the Exponential-Time Hypothesis . . 135

$5 \quad$ Future Research . . . . . . . . . . . . . . 137

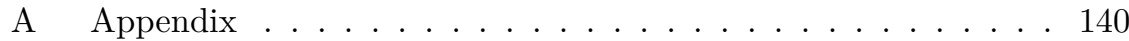


Part I

\section{Introduction}





\section{Chapter 1}

\section{Complexity and constraint problems}

This chapter lightly introduces the topics discussed in this thesis, starting from the absolute basics.

\section{Computational complexity}

Computational complexity theory is an area of theoretical computer science and mathematics which grapples with questions about how hard certain computational problems are to solve. Here we take a look at some important concepts from this field.

\subsection{Problems, instances and algorithms}

A computational problem is a general but exact type of task or question to be answered. It generally has one of more parameters. An example of a problem is the task of determining whether a number $p$ is prime. This problem has one parameter, $p$, which should be a natural number. A solution is a yes/no-answer determining if $p$ is a prime number or not.

Determining if 1001 is a prime number is an instance of the above problem. An instance is a "completely concrete special case of the problem", and is specified by supplying data for all the parameters of the problem.

An algorithm is a sequence of precise step-by-step instructions that one can follow (in a mechanical fashion) to solve a problem. Given data specifying an instance of the problem, the algorithm should lead to a solution. An example of an algorithm is the procedure one learns in school for doing long division. This algorithm solves the "division problem" which has two parameters, both 
of which should be positive whole numbers, and expects as an answer two other numbers, the quotient and a reminder.

To formally describe an algorithm one first need to fix a model of computation. However, it turns out that the choice of computational model does not matter as much as one could expect; all known reasonable alternatives are for our purposes equivalent to the so-called Turing machine (for the details, see for example [3]). The only known exception to this is the quantum computer, a machine that exploits quantum physical effects in order to significantly speed up a certain type of computations. How to build quantum computers large enough to be of practical use is now yet known. For an easy introduction to quantum complexity, see [1].

\subsection{Easy and hard problems}

Some algorithms are better than others. For example: algorithm $A$ may be easier to describe (and program a computer with) than algorithm $B$, or algorithm $A$ may require less resources than algorithm $B$. In the second case one might consider resources such as time (how many steps it takes for the algorithm to complete), space (think of memory requirements of computer programs) or number of random bits needed (for so-called randomized algorithms). We will be interested in time.

The (worst case) running time of an algorithm for some problem is a function $t: \mathbf{N} \rightarrow \mathbf{N}$ such that $t(n)$ is the maximum number of steps used by the algorithm on any instance of size $\leq n$. The size of an instance is the number of bits needed to represent the data specifying it. For the "primality testing" problem the size of an instance is the number of bits needed to describe the number $p$, and hence proportional to the number of digits in $p$.

We will not be particularly interested in the precise running time $t(n)$, this depends heavily on the model of computation. What we care about is instead the asymptotic behavior of $t(n)$ as $n$ grows towards infinity.

A central question will be if $t(n)$ can be bounded from above by some polynomial in $n$. If that is the case we have a polynomial-time algorithm.

For this type of questions it usually does not matter if $n$ specifies the number of bits needed to encode the instance or if it specifies some more natural quantity (for example, in the "primality-testing" example: the number of digits of $p$ ). Because of this, one rarely needs to bother with the precise bitcount.

Observe also that this type of analysis makes sense only for problems with infinitely many instances.

We often think of problems that are solved by some polynomial-time algorithm as easy (or efficiently solvable, or tractable), and problems for which no polynomial-time algorithm exists as difficult. While this (which sometimes is referred to as Cobham-Edmonds thesis since the ideas goes back to the 
papers $[20,32])$ need not be entirely true in practice, it has proved to be a good approximation, or rule of thumb.

\subsection{The classes $\mathbf{P}$ and NP}

A decision problem is a problem that demands a yes/no-answer. The "primality testing" problem is an example of a decision problem.

The complexity class $\mathrm{P}$ (for "polynomial time") consists of all decision problem that can be solved in polynomial time on a Turing machine. An example of a problem in $\mathrm{P}$ is "st connectivity", which is the problem of deciding whether two marked vertices in a given graph are connected. This problem can be solved in polynomial time using, for example, breadth first search. A less obvious fact is that it also can be solved in logarithmic space [82]. Another problem in $\mathrm{P}$ is the "primality testing" problem [2]. The discovery of this fact, which is far from obvious, was a big breakthrough. An interesting and accessible account of the discovery and the algorithm can be found in [12].

The complexity class NP (for "non-deterministic polynomial time") consists of all decision problems that can be solved in polynomial time on a non-deterministic Turing machine. Non-deterministic machines are purely theoretical constructions that does not correspond to anything we know how to build. However, another way to describe the class NP is as the decision problems for which a (deterministic) polynomial-time verification algorithm exists. This verifier is an algorithm that can use polynomially-sized certificates (or, proofs) to check the correctness of all yes-answers. For why these descriptions are equivalent, see for example [89].

Determining whether a given integer $n$ is a composite number is one example of a problem in NP. Every composite number $n$ can by definition be factored into integers $n_{1}$ and $n_{2}$, and these can be used as a certificate. A verification algorithm can take as input the number $n$ and the certificate $\left(n_{1}, n_{2}\right)$, and simply compare the product $n_{1} n_{2}$ with $n$. If the two are equal we know $n$ is a composite number. Observe that the verification algorithm does not care or know about how the factors $n_{1}$ and $n_{2}$ were obtained.

$\mathrm{P}$ is contained in NP; a polynomial-time decision algorithm immediately gives a polynomial-time verification algorithm (using empty certificates). If $\mathrm{P}$ is a proper subclass of NP, or if the two classes are equal, is known as the $\mathrm{P}$ versus NP question, and is perhaps the most well-known problem in theoretical computer science. Intuitively one might think they are different - checking a solution to a puzzle often seem much easier than coming up with the solution in the first place. Indeed, this is also what most working theoretical computer scientists believe. In the year 2000 the Clay Mathematics Institute presented a list of seven mathematical problems. ${ }^{1}$ These problems, called the Millennium Prize Problems, were deemed some of the deepest and most difficult in all of

\footnotetext{
${ }^{1}$ http://www.claymath.org/millennium-problems
} 
mathematics. For a solution to any one of them a prize of one million dollar is awarded. One of the problems is the $\mathrm{P}$ versus $\mathrm{NP}$ question.

\subsection{Comparing the difficulty of problems}

We can sometimes relate the complexity of two problems, even when we do not know the complexity of the individual problems. This is a very important realization, and a foundation for a lot of work in computational complexity theory.

Let $Q$ be the "primality testing" problem and let $R$ be the closely related problem of decomposing a number into its prime factorization. Note that if we have an algorithm for $R$, then we can easily obtain an algorithm for $Q$. We simply run the algorithm for $R$ and check if the factorization consists of a single number. This algorithm is not much slower than the algorithm for $R$, and we can therefore consider $Q$ to be at least as easy as $R$.

We say that the problem $Q$ reduces to the problem $R$ when we in this way can construct an algorithm for $Q$ using as a subroutine a given algorithm for $R$.

An important class of reductions are the polynomial-time reductions. A problem $Q$ is said to be polynomial-time reducible to the problem $R$ if we with the aid of an oracle for $R$ can obtain a polynomial-time algorithm for $Q$. By this we mean that the algorithm may, as a subroutine, make use of an "idealized algorithm" for $R$ that completes in only one time-step. Observe that if $Q$ is polynomial-time reducible to $R$, and if $R$ is solvable in polynomial-time, then also $Q$ is solvable in polynomial-time (we can simply replace every call to the oracle with a call to the polynomial-time algorithm).

An important discovery by Cook [25] (and independently by Levin [75]) is that there exists a problem in NP that all other problems in NP has a polynomial-time reduction to. This problem can therefore be thought of as a hardest problem in NP, and (since we believe $\mathrm{P}$ and NP are different) is unlikely to be solvable in polynomial time. Subsequent work by Karp [59], and thereafter by many researchers, show that a lot of other problems in NP have the same property. A problem $Q$ is called NP-hard if every problem in NP has a polynomial-time reduction to $Q$, and $N P$-complete if it additionally is a member of NP. ${ }^{2}$

Another easy observation concerning polynomial-time reductions is that if some NP-complete problem $Q$ is polynomial-time reducible to another problem $R$ in NP, then also $R$ is NP-complete (by composition of the reductions).

For a more thorough presentation of the things we have discussed in this

\footnotetext{
${ }^{2}$ The kind of polynomial-time reductions we have defined are called Turing reductions. A more restricted type are the Karp reductions (also called polynomial-time many-one reductions). NP-completeness and NP-harness are usually defined with respect to Karp reductions. However, for us this will not be important.
} 

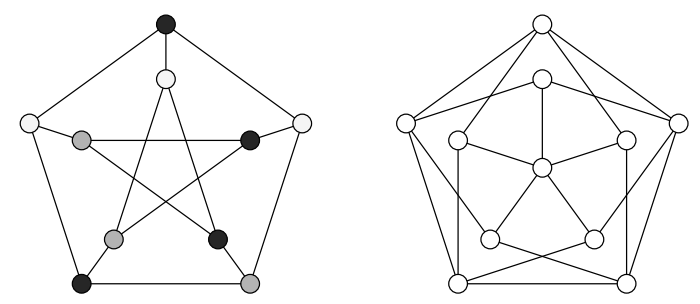

Figure 2.1: The Petersen graph (left) and the Grötzsch graph (right)

section see [36] or one of many other introductory textbooks in computation and complexity, for example [3, 80,89], or algorithms, for example [26].

\section{Some problems}

This section collects a few examples of computational problems that perhaps can clear remaining doubts about what a problem is, and what they usually look like.

Our interest in the problems, which are all NP-hard [36], is motivated mostly by their usefulness when proving that other problems are difficult. However, they are all problems that frequently come up in applications (for example in engineering), and a lot of work has gone into finding good algorithms for them. For just one (very direct) example, consider the traveling salesman problem (defined below). This is a very well-studied problem, see for example the book [74]. One situation where the problem shows up is the following. A drilling machine in a production line drills holes in circuit-boards. In every board numerous holes are to be drilled, and the machine performs the task hole-by-hole by translating the circuit-board in the plane underneath the drill bit. One would like the machine to handle as many boards per hour as possible. To achieve this one needs to find a tour through each spot where a hole is to be drilled such that the total time spent translating the circuit-board is minimized. This is a traveling salesman problem. More information on applications of this kind can be found in [38].

\subsection{The graph k-colorability problem}

Let $k$ be a fixed positive number. The $k$-colorability problem is the problem of deciding whether a given graph $(V, E)$ is $k$-colorable, that is, if there exists a function $f: V \rightarrow\{1, \ldots, k\}$ such that $f(x) \neq f(y)$ whenever $(x, y) \in E$. The numbers $1, \ldots, k$ are here thought of as the colors.

If $k \leq 2$, then a simple polynomial-time algorithm exists. However, for $k \geq 3$ the problem is NP-complete. 
Two small graphs are depicted in Figure 2.1. A 3-coloring is given for the first of the two. What about the second, is it also 3-colorable?

\subsection{The satisfiability problem}

The satisfiability problem was the first problem in NP that was proved to be NP-complete [25]. In this problem we are given a propositional formula in conjunctive normal form. The task is to decide if the formula is satisfiable, that is, if there is an assignment of truth values to the variables in the formula that makes it true.

\subsection{The (positive) one-in-three satisfiability problem}

Define the ternary predicate $R_{1 / 3}$ so that $R_{1 / 3}(x, y, z)$ is true if and only if exactly one of $x, y$ and $z$ is true. In the (positive) one-in-three satisfiability problem, just as in the satisfiability problem, the task is to determine if a given formula is satisfiable. The difference is that here the formula has a special form; it must be a conjunction of atoms of the type $R_{1 / 3}(x, y, z)$, with $x, y, z$ being variables.

The formula $R_{1 / 3}(x, x, y) \wedge R_{1 / 3}(x, z, x) \wedge R_{1 / 3}(z, y, y)$ is an example of an instance. One easily checks that this particular instance is unsatisfiable since $R_{1 / 3}(x, x, y)$ means that $y$ must be true, which is incompatible with $R_{1 / 3}(z, y, y)$.

\subsection{The traveling salesman problem}

Another well known problem is the traveling salesman problem. In this problem one is given a graph $(V, E)$ and a weight-function $w: E \rightarrow \mathbf{N}$. The vertices $V$ are thought of as cities, and the edges $E$ are thought of as roads. Lengths of the roads are given by the function $w$. The task is to find an as short "tour" of all the cities as possible. That is, a sequence $x_{1}, \ldots, x_{n}$ such that $n=|V|$, $\left\{x_{1}, \ldots, x_{n}\right\}=V$ (visit each city once), and $\left(x_{n}, x_{1}\right) \in E,\left(x_{i}, x_{i+1}\right) \in E$ for $1 \leq i \leq n-1$ (travel on roads), that minimizes the sum

$$
w\left(x_{n}, x_{1}\right)+\sum_{i=1}^{n-1} w\left(x_{i}, x_{i+1}\right) .
$$

\subsection{The maximum independent set problem}

Another optimization problem is the maximum independent set problem. This is the problem of finding an independent set of maximum cardinality, called a maximum independent set, in a given graph $(V, E)$. That is, finding a subset $I \subseteq V$ of maximum cardinality such that no two vertices in $I$ are adjacent in the graph. 


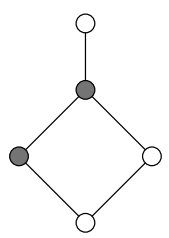

(a)

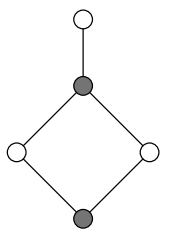

(b)

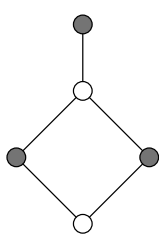

(c)

Figure 2.2: Independent and non-independent sets

A small example is given in Figure 2.2. The filled vertices in Figure 2.2a does not make up an independent set. Those in Figure $2.2 \mathrm{~b}$ on the other hand do. In fact, they constitute a maximal independent set; every proper superset is not an independent set. Note however that they are not a maximum independent set; the independent set displayed in Figure 2.2c is of larger cardinality.

The maximum independent set problem is usually referred to as independent set. It is also called the stable set problem. An independent set is a clique in the complement graph, so the problem is closely related to the clique problem. A variation is the weighted independent set problem. In this problem one is also given a rational nonnegative weight $w_{i}$ for every vertex $i \in V$, and the task is to find an independent set $I$ that maximizes the sum $\sum_{i \in I} w_{i}$. The weighted independent set problem is sometimes called the vertex packing problem.

\subsection{The maximum cut problem}

Our last example is the maximum cut problem. It is defined as the optimization problem where one is given a graph and asked to partition the vertices into two blocks so that the number of crossing edges, edges that go from one of the blocks to the other, is maximized.

The maximum cut problem is usually called max-cut. Also this problem come in a weighted version: weighted max-cut. Here a weight is assigned to every edge. The task is to find a partition of the vertices into two blocks that maximizes the total weight of the crossing edges. The unweighted version of max-cut is sometimes called simple max-cut.

\subsection{Decision versus optimization}

The first three of the problems listed in this section are decision problems (they are all in NP). But the last three are not, they are optimization problems. However, one sometimes refer also to these as NP-problems. What is meant in this case is their "NP-version". In the NP-version an instance also specifies a number $b$, and the question is if there exists a solution with a measure at least as good as $b$. For example, for the independent set problem the question would be: is there an independent set of cardinality at least $b$ ? 
For the three optimization problems in the list it is not hard to show that the decision and the optimization versions are polynomial-time reducible to each other. Let us take the weighted independent set problem as an example. The decision version trivially polynomial-time reduces to the optimization version. Consider the other direction.

First note that we can (in polynomial time) tweak an instance of the optimization version to make all the weights $\left\{w_{i}\right\}_{i \in V}$ integer-valued without changing the set of optimal solutions; multiply the weights by the product of all the denominators. This number is trivially bounded from above by $W^{n}$, where $W$ is the largest denominator and $n=|V|$. The size of its binary representation is therefore polynomial in $n \log W$, which is polynomial in the size of the description of the original instance.

This simplified version of the optimization problem can then be reduced to the decision problem via binary search. The minimum measure of a solution is 0 , and the maximum measure is bounded by $M n$, where $M$ is the largest (integer-valued) weight. To find an independent set of minimum measure we therefore need to query an oracle for the decision version at most $\log _{2} M n$ times. This yields a polynomial-time reduction.

\section{Constraint satisfaction problems}

The constraint satisfaction problems are an important class of problems that captures a wealth of natural and interesting problems in NP. Their study traces back to Montanari [78] and Mackworth [76].

A constraint satisfaction problem (CSP) has a simple form. One is given a set of variables, a set of values (also called labels) and a collection of constraints, and the question is if the variables can be assigned values is a way that satisfies all constraints. The constraints are usually local in the sense that they each constrain a constant number of variables.

For example, assume we have a set of three variables $v_{1}, v_{2}, v_{3}$, and a set $\{a, b, c\}$ of values. Let us require that the labeling of $\left(v_{1}, v_{2}\right)$ is either $(b, b)$ or $(c, c)$. Similarly, require that the labeling of $\left(v_{1}, v_{3}\right)$ matches one of $(a, a),(b, c),(c, b)$ and that $\left(v_{2}, v_{3}\right)$ take values matching one of $(a, b),(b, a),(c, a)$. This is an example of a CSP instance.

Figure 3.1 pictures this instance in what is known as a microstructure graph (sometimes called a potato picture). In this graph there is a vertex for every variable-value pair, and an edge between vertices whose variable-value pairs are compatible with the constraints. The vertices in the graph are called points. Note for example that there is an edge from the point $\left(v_{1}, b\right)$ to the point $\left(v_{3}, c\right)$ because $(b, c)$ is one of the four ways in which we are allowed to label the variables $\left(v_{1}, v_{3}\right)$. By a potato we mean the vertices in the graph associated with a certain variable, in the picture these are marked by shaded regions.

The satisfiability question can now be phrased as: Is is possible to pick one 


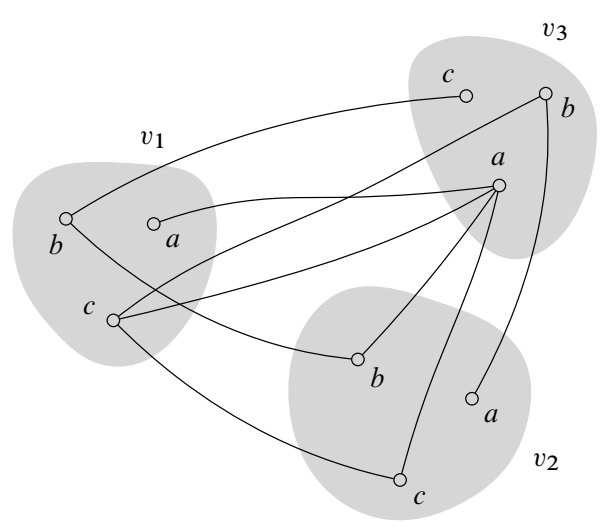

Figure 3.1: A microstructure graph

point in each potato in a way compatible with the edges (so that every two of the chosen points are adjacent)? In our case the answer is clearly yes. For $v_{1}$ we pick $c$, for $v_{2}$ we pick $c$ and for $v_{3}$ we pick $a$. So, the instance is satisfiable.

In general CSPs are difficult to solve. However, by restricting the so-called constraint language one can obtain tractable problems.

Each of the constraints in the example above can be expressed as a pair $\left(\left(v_{i}, v_{j}\right), R_{k}\right)$, where $\left(v_{i}, v_{j}\right)$ denotes the variables to constrain and $R_{k}$ is a binary relation on the domain with which the labeling of $\left(v_{i}, v_{j}\right)$ must be compatible. This will be our usual way of describing constraints. The first part of the constraint $\left(\left(v_{i}, v_{j}\right), R_{k}\right)$, the pair $\left(v_{i}, v_{j}\right)$, is called the constraint scope, and the second part, the relation $R_{k}$, is called the constraint relation.

A constraint language is simply a set of relations, and in the CSP restricted to a certain constraint language $\Gamma$ only constraints over the relations in $\Gamma$ are allowed. The example above describes an instance using three constraint relations, $R_{1,2}=\{(b, b),(c, c)\}, R_{1,3}=\{(a, a),(b, c),(c, a),(c, b)\}$, and $R_{2,3}=$ $\{(a, b),(b, a),(c, a)\}$. It is therefore an instance of the CSP restricted to the constraint language $\left\{R_{1,2}, R_{1,3}, R_{2,3}\right\}$.

Let us now define the constraint satisfaction problems a bit more formally. Let $A$ be a finite domain ${ }^{3}$ set, and let $\Gamma$ be a finite constraint language on $A$. The constraint satisfaction problem restricted to $\Gamma$, denoted $\operatorname{CSP}(\Gamma)$, is the following decision problem. An instance is given by a set $V$ of variables and collection $C$ of constraints. Every constraint is described by a pair $(s, R)$ where the constraint relation $R$ is a member of $\Gamma$ and the constraint scope $s$ is a tuple of variables used to pick out the variables to constrain using $R$. A solution is an assignment of domain values to the variables in a way compatible with all

\footnotetext{
${ }^{3}$ Also infinite domain constraint satisfaction problems have been studied, see for example [9].
} 
constraints, that is, a function $\varphi: V \rightarrow A$ such that $\left(\varphi\left(s_{1}\right), \ldots, \varphi\left(s_{m}\right)\right) \in R$ for every constraint $\left(\left(s_{1}, \ldots, s_{m}\right), R\right)$. The question is if a solution exists.

We already claimed that many NP-problems are expressible as CSPs. As a first example, let $\neq_{A}$ be the disequality relation on $A$, that is, the relation $\{(x, y): x, y \in A, x \neq y\}$. One easily verifies that $\operatorname{CSP}\left(\left\{\neq_{A}\right\}\right)$ is exactly the $|A|$-colorability problem.

A whole family of problems of this type are the graph $H$-coloring problems. Let $H$ be an undirected graph, and let $E$ be the binary symmetric relation described by its edges. The graph $H$-coloring problem is then the same problem as $\operatorname{CSP}(\{E\})$. Hell and Nešetřil [45] obtained for these problems the following result.

Theorem 3.1. If $H$ is bipartite then the $H$-coloring problem is in P. If $H$ is not bipartite then the $H$-coloring problem is NP-complete.

If $\Gamma$ is a constraint language on the Boolean domain, then $\operatorname{CSP}(\Gamma)$ is referred to as a generalized satisfiability problem and usually denoted $\operatorname{SAT}(\Gamma)$. The computational complexity of the problems of this type was studied by Schaefer [84] who obtained the following classification.

Theorem 3.2. If $\Gamma$ satisfies any one of the conditions (i)-(vi) below, then $\mathrm{SAT}(\Gamma)$ is in $P$, otherwise $\operatorname{SAT}(\Gamma)$ is $N P$-complete.

(i) Every relation in $\Gamma$ is 0 -valid.

(ii) Every relation in $\Gamma$ is 1-valid.

(iii) Every relation in $\Gamma$ is weakly positive.

(iv) Every relation in $\Gamma$ is weakly negative.

(v) Every relation in $\Gamma$ is affine.

(vi) Every relation in $\Gamma$ is bijunctive.

The exact meaning of the terminology in the theorem will not be important here. For explanations see Schaefer's paper.

That the CSPs manage to collect a large class of problems in a single simple framework is certainly a useful property. Another interesting property of CSPs is that they never appear to be of intermediate complexity (that is, neither polynomial-time solvable, nor NP-complete). This led Feder and Vardi [33] to what has come to be a very well-known conjecture.

Conjecture 3.3 (The dichotomy conjecture). Let $\Gamma$ be a finite constraint language on a finite domain. Then, $\operatorname{CSP}(\Gamma)$ is either in $P$ or $N P$-complete.

It is known from work by Ladner [72] that if $\mathrm{P}$ and NP are different, then NP contains problems of intermediate complexity. What the dichotomy conjecture says is that the large class of CSPs avoids these intermediate problems.

A lot of work has been aimed towards a proof of the dichotomy conjecture and towards a classification for $\operatorname{CSP}(\Gamma)$ analogous to the one for $\operatorname{SAT}(\Gamma)$ given by Schaefer's theorem. This program has not yet reached its ultimate goal. 
It has however yielded a number of impressive partial results: Bulatov [13] extended Schaefer's classification to three-element domains. Barto, Kozik and Niven [7] generalized Hell and Nešetřil's classification to directed graphs with no sources or sinks. For so-called maximal constraint languages and conservative constraint languages classifications were obtained in [18] and [14] (see also [4]) respectively. It is known that to confirm the dichotomy conjecture it is sufficient to consider binary constraint languages $[19,33]$.

\subsection{The algebraic approach}

A range of techniques from different areas of mathematics and computer science has been brought to bear on CSPs. Examples include logic (see for example [66]) and graph theory (see for example [46]). One of the most successful has been the so-called algebraic approach. This approach, with was pioneered by Jeavons, Cohen, and Gyssens [52] and Bulatov, Jeavons, and Krokhin [17], makes use of tools from the field of universal algebra.

Something called polymorphisms [11] is central to the algebraic approach. Let $R$ be a $m$-ary relation on $A$. A binary operation $f$ on $A$ (that is, a function $f: A^{2} \rightarrow A$ ) is said to preserve a relation $R$ if whenever

$$
\left(x_{1}, \ldots, x_{m}\right),\left(y_{1}, \ldots, y_{m}\right) \in R
$$

it also holds that

$$
\left(f\left(x_{1}, y_{1}\right), \ldots, f\left(x_{m}, y_{m}\right)\right) \in R .
$$

More generally, a $k$-ary operation $g$ preserves $R$ if it satisfies the corresponding criteria. An operation $f$ is called a polymorphism of a set $\Gamma$ of relations if it preserves all relations in the set. One can think of the polymorphisms of $\Gamma$ as a kind of generalized symmetries of the relations in $\Gamma$.

It is easy to verify that the binary operation max is a polymorphism of the relation $\{(0,1),(1,0),(1,1)\}$, but that $\min$ is not. The projection operations, that is, the operations of the form $\left(x_{1}, \ldots, x_{k}\right) \mapsto x_{i}$, are polymorphisms of all relations and therefore polymorphisms of every constraint language.

Schaefer's theorem can be restated in the language of polymorphisms as follows. ${ }^{4}$

Theorem 3.4. If $\Gamma$ is preserved by any one of the operations (i)-(vi) below, then $\operatorname{SAT}(\Gamma)$ is in $P$, otherwise $\operatorname{SAT}(\Gamma)$ is NP-complete.

(i) The unary constant 0 operation

(ii) The unary constant 1 operation

(iii) The binary operation min

(iv) The binary operation max

\footnotetext{
${ }^{4} \mathrm{~A}$ proof that $\Gamma$ is weakly positive (weakly negative, affine, bijunctive) if and only if $\Gamma$ is preserved by the $\max$ (min, minority, majority) operation is found for example in [28, Lemmas 4.8-4.10].
} 
(v) The ternary minority operation

(vi) The ternary majority operation

Example 3.5. Let us check if $R=\{(0,0,1),(0,1,0),(1,0,0)\}$ yields a tractable constraint language. Clearly $R$ is not preserved by the constant 0 or the constant 1 operation since $(0,0,0),(1,1,1) \notin R$. And, $R$ is not closed under min since $(0,0,1),(0,1,0) \in R$ but $(\min (0,0), \min (0,1), \min (1,0))=(0,0,0) \notin R$. Neither $\max$ preserves $R$. A majority operation is an operation $f$ that obeys the identities $f(x, x, y)=f(x, y, x)=f(y, x, x)=x$. Such an operation $f$ does not preserve $R$ since $(0,0,1),(0,1,0),(1,0,0) \in R$, but $(f(0,0,1), f(0,1,0), f(1,0,0))=$ $(0,0,0) \notin R$. Finally, a minority operation is an operation that satisfies the identities $f(x, x, y)=f(x, y, x)=f(y, x, x)=y$. One easily checks that such an operation can not preserve $R$. By Schaefer's theorem $\operatorname{CSP}(\{R\})$ is therefore NP-complete (which should come as no surprise since $\operatorname{CSP}(\{R\}$ ) is equivalent to the positive one-in-three satisfiability problem).

Polymorphisms are not only useful for SAT. It is known that the complexity of $\operatorname{CSP}(\Gamma)$, for any constraint language over on a finite domain, is determined completely by the polymorphisms of $\Gamma[52]$.

A set of necessary conditions on the polymorphisms of $\Gamma$ for tractability of $\operatorname{CSP}(\Gamma)$ was obtained by Bulatov, Jeavons and Krokhin [17]. For every language failing to satisfy these conditions they could prove NP-completeness. In the same paper they also conjectured that the conditions not only are necessary, but in fact also sufficient. This conjecture, which is a strengthening of the dichotomy conjecture, has come to be known as the algebraic dichotomy conjecture. There are several equivalent formulations of this conjecture (for additional information, see for example [16]). We state a version here which was realized through algebraic work due to Maróti and McKenzie [77].

Conjecture 3.6 (The algebraic dichotomy conjecture). Let $\Gamma$ be a finite core constraint language on a finite domain. If $\Gamma$ is preserved by a weak near unanimity operation, then $\operatorname{CSP}(\Gamma)$ is in $P$, otherwise it is NP-complete.

A language is a core if all of its unary polymorphisms are bijections. It is known that one without loss of generality can assume that a language is of this type. A weak near unanimity operation on $A$ is an operation $f$ such that

$$
f(y, x, \ldots, x)=f(x, y, x, \ldots, x)=\cdots=f(x, \ldots, x, y),
$$

for every $x, y \in A$. Note that the operations in Schaefer's theorem (max, min, minority and majority) are weak near unanimity operations (the unary constant 0 and constant 1 operations are not bijections, so they can not be polymorphisms of a core).

Also the algebraic dichotomy conjecture is widely believed. In order to prove it efficient algorithms need to be found (we noted above that the hardness-part already has been established). Work in this direction has discovered very 
general algorithms, it has also provided a good understanding of the limits of these algorithms, see for example $[6,8,15]$.

For a more thorough treatment of the complexity of constraint satisfaction, see for example [5,29,47]. A broader view covering other aspects than those we have touched upon here can be found for example in the books [30,83].

Those who prefer following a presentation instead of (or as a complement to) reading a survey-paper or book can find audio and video recordings, and slides, of good talks on Internet. Many great talks are for example available on the website [97].

\section{Valued CSPs}

Many problems that people care about are optimization problems; one want to find an object in some collection that (according to some measure) is as good as possible.

One example is the linear programming problem - perhaps one of the most well-known of all computational problems. Many linear programs can be solved efficiently by the simplex method. However, in some cases an exponential number of steps are needed [65], and for quite some time it was unknown whether linear programming could be solved in polynomial time or not. It was big news (see [73] for some of the history) when Khachiyan [60,61] settled this by proving that the ellipsoid method solves the problem in polynomial time (for additional information, see [86, Chapter 13]).

We will focus on the computational complexity of so-called combinatorial optimization problems. These are optimization problems where the set of objects that we want to find the best in is finite.

Several optimization versions of the CSPs discussed in the previous section has been proposed in the literature. These frameworks are able to capture a wealth of interesting combinatorial optimization problems. We start by describing some of these frameworks.

\subsection{The minimum solution problems}

The minimum ones problem $[28,62]$ is one of the simplest of all constraint optimization problems. In this problem, which is an optimization version of $\operatorname{SAT}(\Gamma)$, the objective is to find a solution of minimum weight (which in its simplest form is the number of ones). The minimum solution problem [56] is a generalization of the minimum ones problem to larger domains.

Let $\Gamma$ be a constraint language on the finite domain $A$ and $\nu: A \rightarrow \mathbf{Q}_{\geq 0}$ be an injective function. The minimum solution problems on $(\Gamma, \nu)$, which we denote $\operatorname{MinSol}(\Gamma, \nu)$, is the following optimization problem. An instance is given as a set $V$ of variables, a weight function $w: V \rightarrow \mathbf{Q}_{\geq 0}$ and a set 
$C$ of constraints. The constraints are of the same type as in $\operatorname{CSP}(\Gamma)$. In particular, only constraints over relations in $\Gamma$ are allowed. A solution is a function $\varphi: V \rightarrow A$ such that for every constraint $\left(\left(s_{1}, \ldots, s_{m}\right), R\right)$ it holds that $\left(\varphi\left(s_{1}\right), \ldots, \varphi\left(s_{m}\right)\right) \in R$. The measure (or cost, or objective value) of a solution $\varphi$ is given by the sum $\sum_{i \in V} w(i) \nu(\varphi(i))$, and the objective is to find a solution with as small measure as possible.

On two-element domains the problems coincides with (the weighted version of) MinOnes $(\Gamma)$. For these problems a full classification was obtained in [62]. For maximal constraint languages the complexity was, under a certain conjecture, described in [56]. The complexity of the so-called homogeneous constraint languages was also classified in [56]. Another class that has been investigated is graphs on small sets of vertices, see [58]. An overview of many of the results can be found in [54].

Example 4.1. The weighted independent set problem is one example of a problem that can be phrased as a minimum solution problem. Let $A=\{a, b\}$, $R=\{(a, a),(a, b),(b, a)\}$ and let $\nu: A \rightarrow \mathbf{Q}$ be the function mapping $a$ to 1 and $b$ to 0 . We claim that $\operatorname{MinSol}(\{R\}, \nu)$ in all essence is the weighted independent set problem.

An instance $I$ of weighted independent set corresponds to an instance $I^{\prime}$ of $\operatorname{MinSol}(\{R\}, \nu)$ as follows. Vertices in $I$ corresponds to variables in $I^{\prime}$. An edge between two vertices in $I$ corresponds to a constraint applied to the corresponding variables in $I^{\prime}$. Finally, the vertex weights $\left\{w_{i}\right\}$ in $I$ corresponds to the weight function $i \mapsto w_{i}$ in $I^{\prime}$. This describes a bijection from the instances of weighted independent set to the instances of $\operatorname{MinSol}(\{R\}, \nu)$.

Note that solutions to $I^{\prime}$ corresponds to independent sets in $I$, and that there is a solution to $I^{\prime}$ of measure at most $-m+\sum w_{i}$ if and only if there is a (weighted) independent set in $I$ of weight at least $m$.

\subsection{The minimum cost homomorphism problems}

The extended minimum cost homomorphism problems captures both the constraint satisfaction problems and the minimum solution problems.

Let $\Gamma$ be a constraint language on the finite domain $A$ and let $\Delta$ be a set of functions $A \rightarrow \overline{\mathbf{Q}}_{\geq 0}$. Here $\overline{\mathbf{Q}}_{\geq 0}$ denotes $\mathbf{Q}_{\geq 0} \cup\{\infty\}$. The extended minimum cost homomorphism problem on $(\Gamma, \Delta)$, denoted $\operatorname{Min} \operatorname{CostHom}(\Gamma, \Delta)$, is the following optimization problem. An instance is specified by a set of variables $V$, a family of cost functions $\left\{\nu_{i}\right\}_{i \in V}$, and a set of constraints $C$. The function $\nu_{i}$ is specified as a weighted sum of cost functions in $\Delta$, with all weights being nonnegative. The constraints are specified just as for $\operatorname{CSP}(\Gamma)$, only constraint over relations in $\Gamma$ are allowed. A solution is a function $\varphi: V \rightarrow A$ such that $\left(\varphi\left(s_{1}\right), \ldots, \varphi\left(s_{m}\right)\right) \in R$ for every constraint $\left(\left(s_{1}, \ldots, s_{m}\right), R\right)$, and the measure (or cost) of a solution $\varphi$ is given by the sum $\sum_{i \in V} \nu_{i}(\varphi(i))$. Finding a solution 
with as small measure as possible (or determining that no solution exists) is the objective of the problem.

The family of extended minimum cost homomorphism problems were introduced by Takhanov in [91] as a generalization of the (non-extended) minimum cost homomorphism problems. The difference between the extended and the non-extended minimum cost homomorphism problems is that the extended ones are parametrized by a set of allowed cost functions, while the non-extended are not; An instance of the minimum cost homomorphism problem on $\Gamma$, denoted $\operatorname{MinCostHom}(\Gamma)$, may specify for $\nu_{i}$ any function $A \rightarrow \overline{\mathbf{Q}}_{>0}$.

The minimum cost homomorphism problems were introduced by Gutin, Rafiey, Yeo, and Tso [44] and studied in a series of papers that classified the complexity for different classes of binary languages [40-43]. A complete classification for general constraint languages was obtained by Takhanov in [90].

One can check that $\operatorname{Min} \operatorname{Cost} \operatorname{Hom}(\Gamma)$ and $\operatorname{Min} \operatorname{CostHom}(\Gamma, E)$, where $E$ is the set of all functions $A \rightarrow\{0,1\}$, are polynomial-time inter-reducible. So the collection of minimum cost homomorphism problems is a subcollection of the extended minimum cost homomorphism problems.

\subsection{The maximum constraint satisfaction problems}

The maximum constraint satisfaction problem is another optimization variant of the constraint satisfaction problem. Here the goal it to find an assignment of values to the variables that satisfies as many of the constraints as possible.

A more verbose description is as follows. Let $\Gamma$ be a constraint language on a finite set $A$. The maximum constraint satisfaction problem on $\Gamma$, which we denote $\operatorname{Max} \operatorname{CSP}(\Gamma)$, is the optimization problem where an instance is given by a set of variables $V$, a set of (soft) constraints $C$, and a weight function $w: C \rightarrow \mathbf{Q}_{\geq 0}$. The constraints are described as in $\operatorname{CSP}(\Gamma)$ (so each constraint relation is a member of $\Gamma$ ). A solution is any function $\varphi: V \rightarrow A$, and the measure of a solution $\varphi$ is the weighted (by $w$ ) sum of the constraints it satisfies. MaxCSP is a maximization problem, so the objective is to find a solution with the largest possible measure.

The MaxCSPs are well studied. Their computational complexity was described for languages on the Boolean domain in [27] (see also [28]), on the three-element domain in [55], and on the four-element domain in [57]. The complexity for so-called conservative languages was studied in [31]. Recent results [94] for finite-valued VCSPs (a class of problems we soon will describe) has finally yielded a complete classification for $\operatorname{Max} \operatorname{CSP}(\Gamma)$ on finite domains.

Example 4.2. A well-known problem that can be stated as a MaxCSP is weighted max-cut. Define $R=\{(0,1),(1,0)\}$. It is now straight-forward to verify that $\operatorname{Max} \operatorname{CSP}(\{R\})$ and weighted max-cut are polynomial-time inter-reducible, and that the reductions are very natural (the variables in the Max CSP instance corresponds to the vertices of the graph in the max-cut instance). 


\subsection{The valued constraint satisfaction problems}

The valued constraint satisfaction problems [23,85] make up a very large class of problems. In fact, they capture all of the problems we have introduced this far.

A $k$-ary cost function on $A$ is a function $A^{k} \rightarrow \overline{\mathbf{Q}}_{\geq 0}$. Let $\Delta$ be a set of cost functions on $A$. The valued constraint satisfaction problem on $\Delta$, denoted $\operatorname{VCSP}(\Delta)$, is an optimization problem defined as follows. An instance is given as a set of variables $V$, a set of (valued) constraints $C$, and a weight function $w: C \rightarrow \mathbf{Q}_{\geq 0}$. Every (valued) constraint is described by a pair $(s, f)$ of a constraint scope $s$ and a cost function $f$. The cost function $f$ must be a member of $\Delta$. A solution is an assignment of valued to the variables, that is, a function $\varphi: V \rightarrow A$. The measure of a solution $\varphi$ is the $w$-weighted sum of the costs from all the constraints, with the cost from a particular constraint $\left(\left(s_{1}, \ldots, s_{k}\right), f\right)$ being $f\left(\varphi\left(s_{1}\right), \ldots, \varphi\left(s_{k}\right)\right)$. Finding a solution with as small measure as possible is the goal.

To see that the VCSP-framework is very general, let $\Gamma$ be a constraint language on some finite set $A$. Define $\Delta_{0,1}$ as the set that for every $R \in \Gamma$ contains a function $f_{R}$ that is constructed as follows. Assume $R$ is $k$-ary, then $f_{R}$ is a $k$-ary function such that $f_{R}(x)=0$ if $x \in R$, and $f_{R}(x)=1$ otherwise. It is now easy to see that $\operatorname{Max} \operatorname{CSP}(\Gamma)$ corresponds to $\operatorname{VCSP}\left(\Delta_{0,1}\right)$. Similarly, $\operatorname{MinCostHom}(\Gamma, \Delta)$ corresponds to $\operatorname{VCSP}\left(\Delta_{0, \infty} \cup \Delta\right)$, where $\Delta_{0, \infty}$ is defined like $\Delta_{0,1}$, except that the functions are $0 / \infty$-valued instead of $0 / 1$-valued. So, the VCSPs contain among other problems every CSP, MaxCSP, MinSol and every MinCostHom.

$\operatorname{VCSP}(\Delta)$ was completely classified on the two-element in [23]. For the special case when $\Delta$ is a set of finite-valued functions on a three-element domain the complexity was fully described in [49]. The finite-valued case was cracked for finite domains of arbitrary cardinality by work of Kolmogorov, Thapper and Živný [69,94]. The so-called conservative VCSPs constitute another large class of problems for which the complexity is understood [67].

A complete classification for the complexity of all VCSPs was very recently obtained by Kolmogorov, Krokhin and Rolinek [68]. Their work assumes an algorithm for the tractable CSPs (and therefore does not imply a classification for the CSPs).

\subsection{Techniques}

Many ideas from the algebraic approach to CSPs are applicable also to the study of the optimization versions. The computational complexity of a CSP is (as we have already mentioned) completely determined by the set of polymorphisms of the constraint language. To allow a similar result for VCSPs several extensions of the concept of polymorphisms has been proposed: multimorphisms [23], fractional polymorphisms [21], and weighted polymorphisms [24]. This has been 
successful. It was proved in [24] that the complexity of $\operatorname{VCSP}(\Delta)$ is completely determined by the weighted polymorphisms of $\Delta$.

We will refrain from going into details about these objects. Instead, we settle with an example of the simplest case, the binary multimorphism.

Let $\Delta$ be a valued constraint language on the set $A$. A binary multimorphism of $\Delta$ is a pair $(f, g)$ of binary operations on $A$ such that the inequality

$$
\nu(f(x, y))+\nu(g(x, y)) \leq \nu(x)+\nu(y)
$$

holds for every $\nu \in \Delta$ and every $x, y \in A^{k}$, where $k$ is the arity of $\nu$ and $f(x, y)$ denotes component-wise application of $f$ to $x, y$.

Observe that if $\Delta$ contains only $0 / \infty$-valued functions, then $(f, g)$ is a binary multimorphism of $\Delta$ if and only if $f$ and $g$ are polymorphisms of the corresponding (relational) constraint language.

Assume now that $A=\{0,1\}$. An important binary multimorphism in this case is $(\min , \max )$. The valued constraint language $\Delta$ has this multimorphism if and only if every function in $\Delta$ is a submodular function on $A$. Submodular function minimization is a very important area in combinatorial optimization, and much has been published on the topic. See for example the books $[34,79$, $86,88]$. For applications to valued constraint satisfaction and similar problems, see $[22,70]$.

\subsection{Related areas of research}

The question we focus on is whether a particular optimization problem can be solved (exactly) in polynomial time, or if it is NP-hard. A related question, about approximability, crops up in the following scenario. Suppose we need to solve a NP-hard problem, and that all known algorithms for this problem are too slow to be of practical use. One way of coping with this is to settle with finding solutions that are reasonably good, but perhaps not optimal. In the area of approximability one studies to what quality problems can be approximately solved in polynomial time.

Let us take the NP-hard problem max-cut as an example. It was shown in [37] that there is a randomized polynomial-time algorithm that is guaranteed to, in expectation, find a cut of weight at least 0.87856 times the weight of an optimal cut. Doing better than this appears difficult. In fact, it is known that under the unique games conjecture (UGC) [63], doing better is NP-hard [64].

The approximability of VCSPs is well understood under the UGC by work of Raghavendra [81].

Another related area of research is optimization in the so-called oracle model. A class of functions on a finite domain is called oracle-tractable if there is an algorithm that, given an oracle for the evaluation of a $n$-ary function in the class, computes a minimizer in time polynomial in $n$. Submodular functions are oracle-tractable on distributive lattices [51,87], and for diamonds there is a 
pseudo-polynomial-time algorithm [71]. Submodular functions on some more general lattices has also been proved oracle-tractable [70]. Other examples of oracle-tractable classes of functions include bisubmodular functions [35] and skew bisubmodular functions [48].

Additional information about the valued constraint satisfaction problems can be found in [96]. See also [53]. 


\section{Chapter 2}

\section{Contributions}

Here we summarize our main contributions and list of a few open questions.

\section{Main contributions}

\section{$1.1 \quad$ Paper 1}

Hannes Uppman, Max-Sur-CSP on Two Elements, in Principles and Practice of Constraint Programming: 18th International Conference (CP 2012) (Michela Milano, ed.), Lecture Notes in Computer Science (LNCS), vol. 7514, 2013, pp. 38-54, doi 10.1007/978-3-642-33558-7_6

This paper studies the complexity of the surjective maximum constraint satisfaction problems (MaxSurCSP $(\Gamma))$. These problems are variants of Max CSPs where a satisfying mapping of the variables to values is required to be surjective.

The main result is a full classification on the two-element domain (Theorem 2.1). It turns out that there are two quite different tractable cases. The first is problems on supermodular constraint languages. Such problems can be solved by known techniques. The other case is more interesting. To handle it a polynomial-time algorithm (Near-Solutions, pp. 50-51) for a generalization of the minimum cut problem is designed. This algorithm may be of independent interest. The main property used by the algorithm is that a polynomial upper bound can be derived for the number of $\alpha$-optimal solutions (Lemma 3.9).

\section{$1.2 \quad$ Paper 2}

Hannes Uppman, The Complexity of Three-Element Min-Sol and Conservative Min-Cost-Hom, in Automata, Languages, and Programming: 40th International Colloquium, (ICALP 2013) (Fedor V. Fomin, Rūsinsš Freivalds, Marta Kwiatkowska, and David Peleg, 
eds.), Lecture Notes in Computer Science (LNCS), vol. 7965, 2013, pp. 804-815, doi 10.1007/978-3-642-39206-1_68

Takhanov had in [90] obtained a complete classification for the minimum cost homomorphism problems, and in [91] started to explore the extended minimum cost homomorphism problems. All of his tractability results had been proven by a reduction to weighted independent set on perfect graphs, which is polynomialtime solvable [39]. However, it was known that this method could not handle all tractable cases. A problematic minimum solution problem had for example been discovered in [58], and had been solved by algorithms for the critical independent set problem [95].

This paper answers the question whether other types of "strange" threeelement MinSols exists. The answer is: no. All tractable cases are solved either by Takhanovs techniques or by what is known as the basic linear programming relaxation (BLP). The use of the BLP relies on a (at the time very recent) characterization of its power by Thapper and Živný [93].

The main result is a complete classification of the complexity of the minimum solutions problems on three-element domains (Theorem 3.13). Another contribution is a full classification of the extended minimum cost homomorphism problems on conservative languages (Theorem 3.9). This completes work started by Takhanov in [91].

\subsection{Paper 3}

Hannes Uppman, Computational Complexity of the Extended Minimum Cost Homomorphism Problem on Three-Element Domains, in 31st International Symposium on Theoretical Aspects of Computer Science, (STACS 2014) (Ernst W. Mayr and Natacha Portier, eds.), Leibniz International Proceedings in Informatics (LIPIcs), vol. 25, 2014, pp. 651-662, doi 10.4230/LIPIcs.STACS.2014.651

The classification for the three-element minimum solution problems obtained in Paper 2 is in this paper extended to the larger family of extended minimum cost homomorphism problems (Theorem 1.1). On the way to this result a characterization of wpp-definability [92] in terms of fractional polymorphisms is proved (Proposition 4.4). This result complements a similar characterization of expressibility using fractional polymorphisms given by Cohen, Cooper and Jeavons [21]. It is used for example to prove that constants can be added to cores (Proposition 5.2) in the same way as done for CSPs [17].

Very recent work by Kolmogorov, Krokhin and Rolinek [68] fully classifies the complexity of all valued constraint satisfaction problems and thereby supersedes the results in Papers 2 and 3.

\subsection{Paper 4}

Peter Jonsson, Victor Lagerkvist, Johannes Schmidt, and Hannes Uppman, 
Relating the Time Complexity of Optimization Problems in Light of the Exponential-Time Hypothesis,

in Mathematical Foundations of Computer Science 2014: 39th International Symposium, (MFCS 2014) (Erzsébet Csuhaj-Varjú, Martin Dietzfelbinger, and Zoltán Ésik, eds.), Lecture Notes in Computer Science (LNCS), vol. 8635, 2014, pp. 408-419, doi 10.1007/978-3-662-44465-8_35

This paper studies NP-hard optimization problems with the aid of a certain restrictive kind of reductions. This allows the complexity of the problems to be related in a fairly precise manner.

Let $C$ be a family of problems. A problem $A$ in $C$ is called an easiest NP-hard problem in $C$ if: $A$ is NP-hard and whenever $B$ is another NP-hard problem in $C$ that is solvable in time $O\left(c^{n}\right)$ for some constant $c$ then also $A$ is solvable in time $O\left(c^{n}\right)$. An easiest NP-hard problem is obtained both for the family of weighted MaxOnes problems (Theorem 3.3) and the family of finite-valued VCSPs (Theorem 3.4).

Some connections to the exponential-time hypothesis [50] are also established. It is for example proved that if $\Gamma$ is a finite constraint language such that MaxOnes is NP-hard, then unweighted MaxOnes $(\Gamma)$ is solvable in sub-exponential time if and only if the exponential time hypothesis if false (Theorem 4.4).

\section{A few open problems}

Here we list a few open problems. We allow ourselves to use some terminology and notation from the associated papers.

1. A better bound (Paper 1).

Lemma 3.9 gives an upper bound for the cardinality of the set of $\alpha$ optimal solutions to the generalized minimum cut problem. This bound is probably far from optimal. Finding a tight bound would be satisfying, and is probably a not too difficult task.

2. A more direct algorithm (Paper 1).

The algorithm developed for problems on languages of type almost-minmin is in some sense quite indirect. To find a single optimal solution we compute a large set of close-to-optimal solutions which we know must contain all the optimal ones. Is there a more direct approach?

3. A more general algorithm (Paper 1).

The generalized minimum cut problem that is solved by our algorithm is a two-valued problem; a solution maps each vertex to one of two blocks, forming a two-partition of the vertices. Is there a generalization of the minimum $k$-cut problem (for $k>2$ ) that could be solved by the same 
kind of techniques? This is an interesting question since a positive answer could generalize the almost-min-min languages to larger domains.

4. Dependence on the largest arity (Paper 1).

The running time of the algorithm for almost-min-min languages has an unhealthy dependence on the largest arity of a relation in the constraint language. Can this behavior be avoided, or at least mitigated?

5. Infinite languages (Paper 1).

This question is related to the previous one. Our classification holds only for finite constraint languages. Can it be extended to include also the infinite ones?

6. Classification for larger domains (Paper 1).

This task is related to question 3. A classification for the complexity of the problems on arbitrary finite domains would be nice, but is probably not that easy to obtain. Important clues could probably be found by attacking the three-element problems.

7. Classification for surjective VCSPs (Paper 1).

Could our classification be extended to the larger class of surjective VCSPs on two-elements? A very ambitious goal would be to classify surjective VCSPs on arbitrary finite domains. Note however that already on the three-element domain there are surjective CSPs of unknown complexity [10].

8. Improve Theorem 3.2 (Paper 4).

We do not succeed in finding a single easiest language for unweighted MaxOnes, we do however come fairly close in Theorem 3.2. Is is possible to improve this theorem?

9. General VCSPs (Paper 4).

In Theorem 3.4 we obtain an easiest finite-valued VCSP. It would be nice to relax the finiteness restriction and obtain an easiest general-valued VCSP. This would generalize Theorems 3.3 and 3.4.

10. Weighted and unweighted MaxOnes (Paper 4).

Let $\Gamma$ be some finite Boolean constraint language such that $\operatorname{Max} O n e s(\Gamma)$ is NP-hard. It was proved in Theorem 4.4 that unweighted MaxOnes $(\Gamma)$ is solvable in sub-exponential time if and only if the exponential time hypothesis is false. Does this hold also for the weighted version of MaxOnes? 


\section{Bibliography}

[1] Scott Aaronson, The Limits of Quantum Computers, Scientific American 298 (2008), 62-69, doi 10.1038/scientificamerican0308-62.

[2] Manindra Agrawal, Neeraj Kayal, and Nitin Saxena, PRIMES is in P, Annals of Mathematics. Second Series 160 (2004), no. 2, 781-793, doi 10.4007/annals.2004.160.781.

[3] Sanjeev Arora and Boaz Barak, Computational Complexity: A Modern Approach, Cambridge University Press, New York, NY, USA, 2009.

[4] Libor Barto, The Dichotomy for Conservative Constraint Satisfaction Problems Revisited, in 26th Annual IEEE Symposium on Logic in Computer Science (LICS 2011), 2011, pp. 301-310, doi 10.1109/LICS.2011.25.

[5] _ Constraint Satisfaction Problem and Universal Algebra, ACM SIGLOG News 1 (2014), no. 2, 14-24, doi 10.1145/2677161.2677165.

[6] Libor Barto and Marcin Kozik, Constraint Satisfaction Problems of Bounded Width, in Proceedings of the 50th Annual IEEE Symposium on Foundations of Computer Science (FOCS 2009), 2009, pp. 595-603, doi 10.1109/FOCS.2009.32.

[7] Libor Barto, Marcin Kozik, and Todd Niven, The CSP Dichotomy Holds for Digraphs with No Sources and No Sinks (A Positive Answer to a Conjecture of Bang-Jensen and Hell), SIAM Journal on Computing 38 (2009), no. 5, 1782-1802, doi 10.1137/070708093.

[8] Joel Berman, Paweł Idziak, Petar Marković, Ralph McKenzie, Matthew Valeriote, and Ross Willard, Varieties with few subalgebras of powers, Transactions of the American Mathematical Society 362 (2010), no. 3, 1445-1473, doi 10.1090/S00029947-09-04874-0.

[9] Manuel Bodirsky, Constraint Satisfaction Problems with Infinite Templates, in Complexity of Constraints (Nadia Creignou, Phokion G. Kolaitis, and Heribert Vollmer, eds.), Lecture Notes in Computer Science, vol. 5250, 2008, pp. 196-228, doi 10.1007/978-3-540-92800-3_8.

[10] Manuel Bodirsky, Jan Kára, and Barnaby Martin, The complexity of surjective homomorphism problems - a survey, Discrete Applied Mathematics 160 (2012), no. 12, 1680-1690, doi 10.1016/j.dam.2012.03.029. 
[11] V. G. Bodnarchuk, L. A. Kaluzhnin, V. N. Kotov, and B. A. Romov, Galois theory for Post algebras, I, II. I, Kibernetika (Kiev) 3 (1969), 1-10; II, Kibernetika (Kiev) 5 (1969), 1-9 (Russian); English transl. in I, Cybernetics 5 (1969), no. 3, 243-252, doi 10.1007/BF01070906; II, Cybernetics 5 (1969), no. 5, 531-539, doi 10.1007/BF01267873.

[12] Folkmar Bornemann, PRIMES is in P: a breakthrough for "Everyman", Notices of the American Mathematical Society 50 (2003), no. 5, 545-552, available at http://www.ams.org/notices/200305/fea-bornemann.pdf.

[13] Andrei A. Bulatov, A dichotomy theorem for constraint satisfaction problems on a 3-element set, Journal of the ACM 53 (2006), no. 1, 66-120, doi $10.1145 / 1120582.1120584$.

[14] Complexity of Conservative Constraint Satisfaction Problems, ACM Transactions on Computational Logic 12 (2011), no. 4, 24:1-24:66, doi 10.1145/1970398.1970400.

[15] Andrei Bulatov and Víctor Dalmau, A Simple Algorithm for Mal'tsev Constraints, SIAM Journal on Computing 36 (2006), no. 1, 16-27, doi 10.1137/050628957.

[16] Andrei A. Bulatov and Matthew A. Valeriote, Recent Results on the Algebraic Approach to the CSP, in Complexity of Constraints (Nadia Creignou, Phokion G. Kolaitis, and Heribert Vollmer, eds.), Lecture Notes in Computer Science, vol. 5250, 2008, pp. 68-92, doi 10.1007/978-3-540-92800-3_4.

[17] Andrei Bulatov, Peter Jeavons, and Andrei Krokhin, Classifying the Complexity of Constraints Using Finite Algebras, SIAM Journal on Computing 34 (2005), no. 3, 720-742, doi 10.1137/S0097539700376676.

[18] Andrei A. Bulatov, Andrei A. Krokhin, and Peter G. Jeavons, The complexity of maximal constraint languages, in Proceedings of the Thirty-Third Annual ACM Symposium on Theory of Computing (STOC 2001), 2001, pp. 667-674, doi $10.1145 / 380752.380868$.

[19] Jakub Bulín, Dejan Delić, Marcel Jackson, and Todd Niven, On the Reduction of the CSP Dichotomy Conjecture to Digraphs, in Principles and Practice of Constraint Programming: 19th International Conference (CP 2013) (Christian Schulte, ed.), Lecture Notes in Computer Science, vol. 8124, 2013, pp. 184-199, doi 10.1007/978-3-642-40627-0_17.

[20] Alan Cobham, The intrinsic computational difficulty of functions, in Logic, Methodology and Philosophy of Science: Proceedings of the 1964 International Congress (Yehoshua Bar-Hillel, ed.), 1965, pp. 24-30.

[21] David A. Cohen, Martin C. Cooper, and Peter G. Jeavons, An Algebraic Characterisation of Complexity for Valued Constraints, in Principles and Practice of Constraint Programming - CP 2006: 12th International Conference (CP 2006) (Frédéric Benhamou, ed.), Lecture Notes in Computer Science, vol. 4204, 2006, pp. 107-121, doi 10.1007/11889205_10.

[22] _ Generalising Submodularity and Horn Clauses: Tractable Optimization Problems Defined by Tournament Pair Multimorphisms, Theoretical Computer Science 401 (2008), no. 1-3, 36-51, doi 10.1016/j.tcs.2008.03.015. 
[23] David A. Cohen, Martin C. Cooper, Peter G. Jeavons, and Andrei A. Krokhin, The Complexity of Soft Constraint Satisfaction, Artificial Intelligence 170 (2006), no. 11, 983-1016, doi 10.1016/j.artint.2006.04.002.

[24] David A. Cohen, Martin C. Cooper, Páidí Creed, Peter G. Jeavons, and Stanislav Živný, An Algebraic Theory of Complexity for Discrete Optimization, SIAM Journal on Computing 42 (2013), no. 5, 1915-1939, doi 10.1137/130906398.

[25] Stephen A. Cook, The Complexity of Theorem-Proving Procedures, in Proceedings of the Third Annual ACM Symposium on Theory of Computing (STOC 1971), 1971, pp. 151-158, doi 10.1145/800157.805047.

[26] Thomas H. Cormen, Charles E. Leiserson, Ronald L. Rivest, and Clifford Stein, Introduction to Algorithms, MIT Press, 2009.

[27] Nadia Creignou, A dichotomy theorem for maximum generalized satisfiability problems, Journal of Computer and System Sciences 51 (1995), no. 3, 511-522, doi 10.1006/jcss.1995.1087.

[28] Nadia Creignou, Sanjeev Khanna, and Madhu Sudan, Complexity Classifications of Boolean Constraint Satisfaction Problems, Society for Industrial and Applied Mathematics, Philadelphia, PA, USA, 2001, doi 10.1137/1.9780898718546.

[29] Nadia Creignou, Phokion G. Kolaitis, and Heribert Vollmer (eds.), Complexity of Constraints: An Overview of Current Research Themes, Lecture Notes in Computer Science, vol. 5250, 2008, doi 10.1007/978-3-540-92800-3.

[30] Rina Dechter, Constraint processing, Elsevier Morgan Kaufmann, 2003.

[31] Vladimir Deineko, Peter Jonsson, Mikael Klasson, and Andrei Krokhin, The Approximability of MAX CSP with Fixed-value Constraints, Journal of the ACM 55 (2008), no. 4, 16:1-16:37, doi 10.1145/1391289.1391290.

[32] Jack Edmonds, Paths, trees, and flowers, Canadian Journal of Mathematics. Journal Canadien de Mathématiques 17 (1965), 449-467, doi 10.4153/CJM-1965045-4.

[33] Tomás Feder and Moshe Y. Vardi, The Computational Structure of Monotone Monadic SNP and Constraint Satisfaction: A Study through Datalog and Group Theory, SIAM Journal on Computing 28 (1998), no. 1, 57-104, doi 10.1137/S0097539794266766.

[34] Satoru Fujishige, Submodular Functions and Optimization, Elsevier, 2005.

[35] Satoru Fujishige and Satoru Iwata, Bisubmodular function minimization, SIAM Journal on Discrete Mathematics 19 (2005), no. 4, 1065-1073, doi 10.1137/S0895480103426339.

[36] Michael R. Garey and David S. Johnson, Computers and Intractability: A Guide to the Theory of NP-Completeness, W. H. Freeman \& Co., New York, NY, USA, 1979.

[37] Michel X. Goemans and David P. Williamson, Improved Approximation Algorithms for Maximum Cut and Satisfiability Problems Using Semidefinite Programming, Journal of the ACM 42 (1995), no. 6, 1115-1145, doi 10.1145/227683.227684.

[38] M. Grötschel, M. Jünger, and G. Reinelt, Optimal control of plotting and drilling machines: A case study, Zeitschrift für Operations Research 35 (1991), no. 1, 61-84, doi 10.1007/BF01415960. 
[39] M. Grötschel, L. Lovász, and A. Schrijver, Relaxations of Vertex Packing, Journal of Combinatorial Theory, Series B 40 (1986), no. 3, 330-343, doi 10.1016/00958956(86)90087-0.

[40] Arvind Gupta, Pavol Hell, Mehdi Karimi, and Arash Rafiey, Minimum Cost Homomorphisms to Reflexive Digraphs, in LATIN 2008: Theoretical Informatics: 8th Latin American Symposium (LATIN 2008) (Eduardo Sany Laber, Claudson Bornstein, Loana Tito Nogueira, and Luerbio Faria, eds.), Lecture Notes in Computer Science, vol. 4957, 2008, pp. 182-193, doi 10.1007/978-3-540-78773-0_16.

[41] Gregory Gutin, Arash Rafiey, and Anders Yeo, Minimum cost and list homomorphisms to semicomplete digraphs, Discrete Applied Mathematics 154 (2006), no. 6, 890-897, doi 10.1016/j.dam.2005.11.006.

[42] _ Minimum Cost Homomorphism Dichotomy for Oriented Cycles, in Algorithmic Aspects in Information and Management: 4th International Conference (AAIM 2008) (Rudolf Fleischer and Jinhui Xu, eds.), Lecture Notes in Computer Science, vol. 5034, 2008, pp. 224-234, doi 10.1007/978-3-540-68880-8_22.

[43] Gregory Gutin, Pavol Hell, Arash Rafiey, and Anders Yeo, A dichotomy for minimum cost graph homomorphisms, European Journal of Combinatorics 29 (2008), no. 4, 900-911, doi 10.1016/j.ejc.2007.11.012.

[44] Gregory Gutin, Arash Rafiey, Anders Yeo, and Michael Tso, Level of repair analysis and minimum cost homomorphisms of graphs, Discrete Applied Mathematics 154 (2006), no. 6, 881-889, doi 10.1016/j.dam.2005.06.012.

[45] Pavol Hell and Jaroslav Nešetřil, On the Complexity of H-coloring, Journal of Combinatorial Theory, Series B 48 (1990), no. 1, 92-110, doi 10.1016/00958956(90)90132-J.

[46] _ Graphs and homomorphisms, Oxford University Press, Oxford, 2004, doi 10.1093/acprof:oso/9780198528173.001.0001.

[47] _ Colouring, constraint satisfaction, and complexity, Computer Science Review 2 (2008), no. 3, 143-163, doi 10.1016/j.cosrev.2008.10.003.

[48] Anna Huber and Andrei Krokhin, Oracle tractability of skew bisubmodular functions, SIAM Journal on Discrete Mathematics 28 (2014), no. 4, 1828-1837, doi 10.1137/130936038.

[49] Anna Huber, Andrei Krokhin, and Robert Powell, Skew Bisubmodularity and Valued CSPs, SIAM Journal on Computing 43 (2014), no. 3, 1064-1084, doi $10.1137 / 120893549$.

[50] Russell Impagliazzo and Ramamohan Paturi, On the Complexity of k-SAT, Journal of Computer and System Sciences 62 (2001), no. 2, 367-375, doi $10.1006 /$ jcss.2000.1727.

[51] Satoru Iwata, Lisa Fleischer, and Satoru Fujishige, A combinatorial strongly polynomial algorithm for minimizing submodular functions, Journal of the ACM 48 (2001), no. 4, 761-777, doi 10.1145/502090.502096.

[52] Peter Jeavons, David Cohen, and Marc Gyssens, Closure properties of constraints, Journal of the ACM 44 (1997), no. 4, 527-548, doi 10.1145/263867.263489. 
[53] Peter Jeavons, Andrei Krokhin, and Stanislav Živný, The Complexity of Valued Constraint Satisfaction, Bulletin of the European Association for Theoretical Computer Science (EATCS) 113 (2014), 21-55, available at www.eatcs.org/beatcs/index.php/beatcs/article/view/266.

[54] Peter Jonsson and Gustav Nordh, Introduction to the Maximum Solution Problem, in Complexity of Constraints (Nadia Creignou, Phokion G. Kolaitis, and Heribert Vollmer, eds.), Lecture Notes in Computer Science, vol. 5250, 2008, pp. 255-282, doi 10.1007/978-3-540-92800-3_10.

[55] Peter Jonsson, Mikael Klasson, and Andrei Krokhin, The Approximability of Three-valued MAX CSP, SIAM Journal on Computing 35 (2006), no. 6, 13291349, doi 10.1137/S009753970444644X.

[56] Peter Jonsson, Fredrik Kuivinen, and Gustav Nordh, MAX ONES Generalized to Larger Domains, SIAM Journal on Computing 38 (2008), no. 1, 329-365, doi $10.1137 / 060669231$.

[57] Peter Jonsson, Fredrik Kuivinen, and Johan Thapper, Min CSP on Four Elements: Moving beyond Submodularity, in Principles and Practice of Constraint Programming - CP 2011: 17th International Conference (CP 2011) (Jimmy Lee, ed.), Lecture Notes in Computer Science, vol. 6876, 2011, pp. 438-453, doi 10.1007/978-3-642-23786-7_34.

[58] Peter Jonsson, Gustav Nordh, and Johan Thapper, The Maximum Solution Problem on Graphs, in Mathematical Foundations of Computer Science 2007: 32nd International Symposium (MFCS 2007) (Luděk Kučera and Antonín Kučera, eds.), Lecture Notes in Computer Science, vol. 4708, 2007, pp. 228-239, doi 10.1007/9783-540-74456-6 22.

[59] Richard M. Karp, Reducibility Among Combinatorial Problems, in Complexity of Computer Computations (Raymond E. Miller and James W. Thatcher, eds.), The IBM Research Symposia Series, 1972, pp. 85-103, doi 10.1007/978-1-4684-2001-2_9.

[60] L. G. Khachiyan, A polynomial algorithm in linear programming, Doklady Akademii Nauk SSSR 244 (1979), no. 5, 1093-1096 (Russian); English transl., Soviet Mathematics. Doklady 20 (1979), 191-194.

[61] _ Polynomial algorithms in linear programming, Zhurnal Vychislitel'noi Matematiki i Matematicheskoi Fiziki 20 (1980), no. 1, 51-68, 260 (Russian); English transl., U.S.S.R. Computational Mathematics and Mathematical Physics 20 (1980), no. 1, 53-72, doi 10.1016/0041-5553(80)90061-0.

[62] Sanjeev Khanna, Madhu Sudan, Luca Trevisan, and David P. Williamson, The Approximability of Constraint Satisfaction Problems, SIAM Journal on Computing 30 (2001), no. 6, 1863-1920, doi 10.1137/S0097539799349948.

[63] Subhash Khot, On the Power of Unique 2-prover 1-round Games, in Proceedings of the Thirty-Fourth Annual ACM Symposium on Theory of Computing (STOC 2002), 2002, pp. 767-775, doi 10.1145/509907.510017.

[64] Subhash Khot, Guy Kindler, Elchanan Mossel, and Ryan O’Donnell, Optimal Inapproximability Results for MAX-CUT and Other 2-Variable CSPs?, SIAM Journal on Computing 37 (2007), no. 1, 319-357, doi 10.1137/S0097539705447372. 
[65] Victor Klee and George J. Minty, How Good Is the Simplex Algorithm?, in Inequalities, III: Proceedings of the Third Symposium on Inequalities (Oved Shisha, ed.), 1972, pp. 159-175.

[66] Phokion G. Kolaitis and Moshe Y. Vardi, A Logical Approach to Constraint Satisfaction, in Complexity of Constraints (Nadia Creignou, Phokion G. Kolaitis, and Heribert Vollmer, eds.), Lecture Notes in Computer Science, vol. 5250, 2008, pp. 125-155, doi 10.1007/978-3-540-92800-3_6.

[67] Vladimir Kolmogorov and Stanislav Živný, The Complexity of Conservative Valued CSPs, Journal of the ACM 60 (2013), no. 2, 10:1-10:38, doi $10.1145 / 2450142.2450146$.

[68] Vladimir Kolmogorov, Andrei Krokhin, and Michal Rolinek, The Complexity of General-Valued CSPs, CoRR (2015), available at http://arxiv.org/abs/1502.07327.

[69] Vladimir Kolmogorov, Johan Thapper, and Stanislav Živný, The Power of Linear Programming for General-Valued CSPs, SIAM Journal on Computing 44 (2015), no. 1, 1-36, doi 10.1137/130945648.

[70] Andrei Krokhin and Benoit Larose, Maximizing Supermodular Functions on Product Lattices, with Application to Maximum Constraint Satisfaction, SIAM Journal on Discrete Mathematics 22 (2008), no. 1, 312-328, doi 10.1137/060669565.

[71] Fredrik Kuivinen, On the complexity of submodular function minimisation on diamonds, Discrete Optimization 8 (2011), no. 3, 459-477, doi 10.1016/j.disopt.2011.04.001.

[72] Richard E. Ladner, On the Structure of Polynomial Time Reducibility, Journal of the ACM 22 (1975), no. 1, 155-171, doi 10.1145/321864.321877.

[73] Eugene L. Lawler, The great mathematical Sputnik of 1979, The Mathematical Intelligencer 2 (1980), no. 4, 191-198, doi 10.1007/BF03028602.

[74] E. L. Lawler, J. K. Lenstra, A. H. G. Rinnooy Kan, and D. B. Shmoys (eds.), The traveling salesman problem: A guided tour of combinatorial optimization, John Wiley \& Sons, Ltd., Chichester, 1985.

[75] L. A. Levin, Universal sequential search problems, Problemy Peredachi Informatsii 9 (1973), 115-116 (Russian); English transl., B. A. Trakhtenbrot, A Survey of Russian Approaches to Perebor (Brute-Force Searches) Algorithms, Annals of the History of Computing 6 (1984), no. 4, 384-400, doi 10.1109/MAHC.1984.10036.

[76] Alan K. Mackworth, Consistency in Networks of Relations, Artificial Intelligence 8 (1977), no. 1, 99-118, doi 10.1016/0004-3702(77)90007-8.

[77] Miklós Maróti and Ralph McKenzie, Existence theorems for weakly symmetric operations, Algebra Universalis 59 (2008), no. 3-4, 463-489, doi 10.1007/s00012008-2122-9.

[78] Ugo Montanari, Networks of constraints: Fundamental properties and applications to picture processing, Information Sciences 7 (1974), 95-132, doi 10.1016/00200255(74)90008-5.

[79] George L. Nemhauser and Laurence A. Wolsey, Integer and combinatorial optimization, John Wiley \& Sons, Inc., New York, 1988.

[80] Christos H. Papadimitriou, Computational complexity, Addison-Wesley, 1994. 
[81] Prasad Raghavendra, Optimal Algorithms and Inapproximability Results for Every CSP?, in Proceedings of the Fortieth Annual ACM Symposium on Theory of Computing (STOC 2008), 2008, pp. 245-254, doi 10.1145/1374376.1374414.

[82] Omer Reingold, Undirected connectivity in log-space, Journal of the ACM $\mathbf{5 5}$ (2008), no. 4, 17:1-17:24, doi 10.1145/1391289.1391291.

[83] Francesca Rossi, Peter van Beek, and Toby Walsh (eds.), Handbook of Constraint Programming, Elsevier Science Inc., New York, NY, USA, 2006.

[84] Thomas J. Schaefer, The Complexity of Satisfiability Problems, in Proceedings of the Tenth Annual ACM Symposium on Theory of Computing (STOC 1978), 1978, pp. 216-226, doi 10.1145/800133.804350.

[85] Thomas Schiex, Hélène Fargier, and Gérard Verfaillie, Valued Constraint Satisfaction Problems: Hard and Easy Problems, in Proceedings of the 14th international joint conference on Artificial intelligence (IJCAI 1995), 1995, pp. 631-637.

[86] Alexander Schrijver, Theory of Linear and Integer Programming, John Wiley \& Sons, Inc., New York, NY, USA, 1986.

[87] _ A combinatorial algorithm minimizing submodular functions in strongly polynomial time, Journal of Combinatorial Theory. Series B 80 (2000), no. 2, 346-355, doi 10.1006/jctb.2000.1989.

[88] _ Combinatorial optimization: Polyhedra and efficiency, Springer-Verlag, Berlin, 2003.

[89] Michael Sipser, Introduction to the Theory of Computation, International Thomson Publishing, 1996.

[90] Rustem Takhanov, A Dichotomy Theorem for the General Minimum Cost Homomorphism Problem, in 27th International Symposium on Theoretical Aspects of Computer Science (STACS 2010) (Jean-Yves Marion and Thomas Schwentick, eds.), Leibniz International Proceedings in Informatics, vol. 5, 2010, pp. 657-668, doi 10.4230/LIPIcs.STACS.2010.2493.

[91] _ Extensions of the Minimum Cost Homomorphism Problem, in Computing and Combinatorics: 16th Annual International Conference (COCOON 2010) (My T. Thai and Sartaj Sahni, eds.), Lecture Notes in Computer Science, vol. 6196, 2010, pp. 328-337, doi 10.1007/978-3-642-14031-0_36.

[92] Johan Thapper, Aspects of a Constraint Optimisation Problem, Ph.D. Thesis, Linköping University, The Institute of Technology, 2010, available at urn.kb.se/resolve?urn=urn:nbn:se:liu:diva-52103.

[93] Johan Thapper and Stanislav Živný, The Power of Linear Programming for Valued CSPs, in Proceedings of the 2012 IEEE 53rd Annual Symposium on Foundations of Computer Science (FOCS 2012), 2012, pp. 669-678, doi 10.1109/FOCS.2012.25.

[94] _ The Complexity of Finite-Valued CSPs, in Proceedings of the FortyFifth Annual ACM Symposium on Theory of Computing (STOC 2013), 2013, pp. 695-704, doi 10.1145/2488608.2488697.

[95] Cun-Quan Zhang, Finding critical independent sets and critical vertex subsets are polynomial problems, SIAM Journal on Discrete Mathematics 3 (1990), no. 3, 431-438, doi 10.1137/0403037. 
[96] Stanislav Živný, The complexity of valued constraint satisfaction problems, Springer, 2012, doi 10.1007/978-3-642-33974-5.

[97] Summer Thematic Program on the Mathematics of Constraint Satisfaction at the Fields Institute, Toronto (Toronto, Canada), 2011, available at www.fields.utoronto.ca/programs/scientific/11-12/constraint/. 


\section{Part II}

\section{Papers}





\section{Papers}

The articles associated with this thesis have been removed for copyright reasons. For more details about these see:

http://urn.kb.se/resolve?urn=urn:nbn:se:liu:diva-116859 


\section{Dissertations}

\section{Linköping Studies in Science and Technology Linköping Studies in Arts and Science \\ Linköping Studies in Statistics \\ Linköpings Studies in Information Science}

\begin{abstract}
Linköping Studies in Science and Technology
No 14 Anders Haraldsson: A Program Manipulation System Based on Partial Evaluation, 1977, ISBN 917372-144-1.
\end{abstract}

No 17 Bengt Magnhagen: Probability Based Verification of Time Margins in Digital Designs, 1977, ISBN 91-7372157-3.

No 18 Mats Cedwall: Semantisk analys av processbeskrivningar i naturligt språk, 1977, ISBN 91- 7372168-9.

No 22 Jaak Urmi: A Machine Independent LISP Compiler and its Implications for Ideal Hardware, 1978, ISBN 91-7372-188-3.

No 33 Tore Risch: Compilation of Multiple File Queries in a Meta-Database System 1978, ISBN 91- 7372-232-4.

No 51 Erland Jungert: Synthesizing Database Structures from a User Oriented Data Model, 1980, ISBN 917372-387-8.

No 54 Sture Hägglund: Contributions to the Development of Methods and Tools for Interactive Design of Applications Softw are, 1980, ISBN 91-7372-404-1.

No 55 Pär Emanuelson: Performance Enhancement in a Well-Structured Pattern Matcher through Partial Evaluation, 1980, ISBN 91-7372-403-3.

No 58 Bengt Johnsson, Bertil Andersson: The HumanComputer Interface in Commercial Systems, 1981, ISBN 91-7372-414-9.

No 69 H. Jan Komorowski: A Specification of an Abstract Prolog Machine and its Application to Partial Evaluation, 1981, ISBN 91-7372-479-3.

No 71 René Reboh: Knowledge Engineering Techniques and Tools for Expert Systems, 1981, ISBN 91-7372489-0.

No 77 Östen Oskarsson: Mechanisms of Modifiability in large Softw are Systems, 1982, ISBN 91- 7372-527-7.

No 94 Hans Lunell: Code Generator Writing Systems, 1983, ISBN 91-7372-652-4.

No 97 Andrzej Lingas: Advances in Minimum Weight Triangulation, 1983, ISBN 91-7372-660-5.

No 109 Peter Fritzson: Tow ards a Distributed Programming Environment based on Incremental Compilation, 1984, ISBN 91-7372-801-2.

No 111 Erik Tengvald: The Design of Expert Planning Systems. An Experimental Operations Planning System for Turning, 1984, ISBN 91-7372- 805-5.

No 155 Christos Levcopoulos: Heuristics for Minimum Decompositions of Polygons, 1987, ISBN 91-7870133-3.

No 165 James W. Goodwin: A Theory and System for NonMonotonic Reasoning, 1987, ISBN 91-7870-183-X.

No 170 Zebo Peng: A Formal Methodology for Automated Synthesis of VLSI Systems, 1987, ISBN 91-7870-225-9.

No 174 Johan Fagerström: A Paradigm and System for Design of Distributed Systems, 1988, ISBN 91-7870301-8.

No 192 Dimiter Driankov: Tow ards a Many Valued Logic of Quantified Belief, 1988, ISBN 91-7870-374-3.
No 213 Lin Padgham: Non-Monotonic Inheritance for an Object Oriented Knowledge Base, 1989, ISBN 917870-485-5.

No 214 Tony Larsson: A Formal Hardware Description and Verification Method, 1989, ISBN 91-7870-517-7.

No 221 Michael Reinfrank: Fundamentals and Logical Foundations of Truth Maintenance, 1989, ISBN 917870-546-0.

No 239 Jonas Löwgren: Knowledge-Based Design Support and Discourse Management in User Interface Management Systems, 1991, ISBN 91-7870-720-X.

No 244 Henrik Eriksson: Meta-Tool Support for Knowledge Acquisition, 1991, ISBN 91-7870-746-3.

No 252 Peter Eklund: An Epistemic Approach to Interactive Design in Multiple Inheritance Hierarchies, 1991, ISBN 91-7870-784-6.

No 258 Patrick Doherty: NML3 - A Non-Monotonic Formalism with Explicit Defaults, 1991, ISBN 917870-816-8

No 260 Nahid Shahmehri: Generalized Algorithmic Debugging, 1991, ISBN 91-7870-828-1.

No 264 Nils Dahlbäck: Representation of DiscourseCognitive and Computational Aspects, 1992, ISBN 91-7870-850-8.

No 265 Ulf Nilsson: Abstract Interpretations and Abstract Machines: Contributions to a Methodology for the Implementation of Logic Programs, 1992, ISBN 917870-858-3.

No 270 Ralph Rönnquist: Theory and Practice of Tensebound Object References, 1992, ISBN 91-7870-873-7.

No 273 Björn Fjellborg: Pipeline Extraction for VLSI Data Path Synthesis, 1992, ISBN 91-7870-880-X.

No 276 Staffan Bonnier: A Formal Basis for Horn Clause Logic with External Polymorphic Functions, 1992, ISBN 91-7870-896-6.

No 277 Kristian Sandahl: Developing Knowledge Management Systems with an Active Expert Methodology, 1992, ISBN 91-7870-897-4.

No 281 Christer Bäckström: Computational Complexity of Reasoning about Plans, 1992, ISBN 91-7870-979-2.

No 292 Mats Wirén: Studies in Incremental Natural Language Analysis, 1992, ISBN 91-7871-027-8.

No 297 Mariam Kamkar: Interprocedural Dynamic Slicing with Applications to Debugging and Testing, 1993, ISBN 91-7871-065-0.

No 302 Tingting Zhang: A Study in Diagnosis Using Classification and Defaults, 1993, ISBN 91-7871-078-2

No 312 Arne Jönsson: Dialogue Management for Natural Language Interfaces - An Empirical Approach, 1993, ISBN 91-7871-110-X.

No 338 Simin Nadjm-Tehrani: Reactive Systems in Physical Environments: Compositional Modelling and Framework for Verification, 1994, ISBN 91-7871-237-8.

No 371 Bengt Savén: Business Models for Decision Support and Learning. A Study of Discrete-Event Manufacturing Simulation at Asea/ ABB 1968-1993, 1995, ISBN 91-7871-494-X. 
No 375 Ulf Söderman: Conceptual Modelling of Mode Switching Physical Systems, 1995, ISBN 91-7871-5164.

No 383 Andreas Kågedal: Exploiting Groundness in Logic Programs, 1995, ISBN 91-7871-538-5.

No 396 George Fodor: Ontological Control, Description, Identification and Recovery from Problematic Control Situations, 1995, ISBN 91-7871-603-9.

No 413 Mikael Pettersson: Compiling Natural Semantics, 1995, ISBN 91-7871-641-1.

No 414 Xinli Gu: RT Level Testability Improvement by Testability Analysis and Transformations, 1996, ISBN 91-7871-654-3.

No 416 Hua Shu: Distributed Default Reasoning, 1996, ISBN 91-7871-665-9.

No 429 Jaime Villegas: Simulation Supported Industrial Training from an Organisational Learning Perspective - Development and Evaluation of the SSIT Method, 1996, ISBN 91-7871-700-0.

No 431 Peter Jonsson: Studies in Action Planning: Algorithms and Complexity, 1996, ISBN 91-7871-7043.

No 437 Johan Boye: Directional Types in Logic Programming, 1996, ISBN 91-7871-725-6.

No 439 Cecilia Sjöberg: Activities, Voices and Arenas: Participatory Design in Practice, 1996, ISBN 91-7871728-0

No 448 Patrick Lambrix: Part-Whole Reasoning in Description Logics, 1996, ISBN 91-7871-820-1.

No 452 Kjell Orsborn: On Extensible and Object-Relational Database Technology for Finite Element Analysis Applications, 1996, ISBN 91-7871-827-9.

No 459 Olof Johansson: Development Environments for Complex Product Models, 1996, ISBN 91-7871-855-4.

No 461 Lena Strömbäck: User-Defined Constructions in Unification-Based Formalisms, 1997, ISBN 91-7871$857-0$

No 462 Lars Degerstedt: Tabulation-based Logic Programming: A Multi-Level View of Query Answering, 1996, ISBN 91-7871-858-9.

No 475 Fredrik Nilsson: Strategi och ekonomisk styrning En studie av hur ekonomiska styrsystem utformas och används efter företagsförvärv, 1997, ISBN 917871-914-3

No 480 Mikael Lindvall: An Empirical Study of Requirements-Driven Impact Analysis in Object-Oriented Softw are Evolution, 1997, ISBN 91-7871-927-5.

No 485 Göran Forslund: Opinion-Based Systems: The Cooperative Perspective on Knowledge-Based Decision Support, 1997, ISBN 91-7871-938-0.

No 494 Martin Sköld: Active Database Management Systems for Monitoring and Control, 1997, ISBN 917219-002-7.

No 495 Hans Olsén: Automatic Verification of Petri Nets in a CLP framew ork, 1997, ISBN 91-7219-011-6.

No 498 Thomas Drakengren: Algorithms and Complexity for Temporal and Spatial Formalisms, 1997, ISBN 917219-019-1.

No 502 Jakob Axelsson: Analysis and Synthesis of Heterogeneou s Real-Time Systems, 1997, ISBN 91-7219-035-3.

No 503 Johan Ringström: Compiler Generation for DataParallel Programming Languages from Two-Level Semantics Specifications, 1997, ISBN 91-7219-045-0.

No 512 Anna Moberg: Närhet och distans - Studier av kommunikationsmönster i satellitkontor och flexibla kontor, 1997, ISBN 91-7219-119-8.
No 520 Mikael Ronström: Design and Modelling of a Parallel Data Server for Telecom Applications, 1998, ISBN 91-7219-169-4.

No 522 Niclas Ohlsson: Tow ards Effective Fault Prevention - An Empirical Study in Software Engineering, 1998, ISBN 91-7219-176-7.

No 526 Joachim Karlsson: A Systematic Approach for Prioritizing Software Requirements, 1998, ISBN 917219-184-8.

No 530 Henrik Nilsson: Declarative Debugging for Lazy Functional Languages, 1998, ISBN 91-7219-197-x.

No 555 Jonas Hallberg: Timing Issues in High-Level Synthesis, 1998, ISBN 91-7219-369-7.

No 561 Ling Lin: Management of 1-D Sequence Data - From Discrete to Continu ous, 1999, ISBN 91-7219-402-2.

No 563 Eva L Ragnemalm: Student Modelling based on Collaborative Dialogue with a Learning Companion, 1999, ISBN 91-7219-412-X

No 567 Jörgen Lindström: Does Distance matter? On geographical dispersion in organisations, 1999, ISBN $91-$ 7219-439-1.

No 582 Vanja Josifovski: Design, Implementation and Evaluation of a Distributed Mediator System for Data Integration, 1999, ISBN 91-7219-482-0.

No 589 Rita Kovordányi: Modeling and Simulating Inhibitory Mechanisms in Mental Image Reinterpretation - Towards Cooperative HumanComputer Creativity, 1999, ISBN 91-7219-506-1.

No 592 Mikael Ericsson: Supporting the Use of Design Knowledge - An Assessment of Commenting Agents, 1999, ISBN 91-7219-532-0.

No 593 Lars Karlsson: Actions, Interactions and Narratives, 1999, ISBN 91-7219-534-7.

No 594 C. G. Mikael Johansson: Social and Organizational Aspects of Requirements Engineering Methods - A practice-oriented approach, 1999, ISBN 91-7219-541$\mathrm{X}$

No 595 Jörgen Hansson: Value-Driven Multi-Class Overload Management in Real-Time Database Systems, 1999 , ISBN 91-7219-542-8.

No 596 Niklas Hallberg: Incorporating User Values in the Design of Information Systems and Services in the Public Sector: A Methods Approach, 1999, ISBN 917219-543-6.

No 597 Vivian Vimarlund: An Economic Perspective on the Analysis of Impacts of Information Technology: From Case Studies in Health-Care towards General Models and Theories, 1999, ISBN 91-7219-544-4.

No 598 Johan Jenvald: Methods and Tools in ComputerSupported Taskforce Training, 1999, ISBN 91-7219547-9.

No 607 Magnus Merkel: Understanding and enhancing translation by parallel text processing, 1999, ISBN 91 7219-614-9.

No 611 Silvia Coradeschi: Anchoring symbols to sensory data, 1999, ISBN 91-7219-623-8.

No 613 Man Lin: Analysis and Synthesis of Reactive Systems: A Generic Layered Architecture Perspective, 1999, ISBN 91-7219-630-0.

No 618 Jimmy Tjäder: Systemimplementering i praktiken En studie av logiker i fyra projekt, 1999, ISBN 917219-657-2.

No 627 Vadim Engelson: Tools for Design, Interactive Simulation, and Visualization of Object-Oriented Models in Scientific Computing, 2000, ISBN 91-7219709-9. 
No 637 Esa Falkenroth: Database Technology for Control and Simulation, 2000, ISBN 91-7219-766-8.

No 639 Per-Arne Persson: Bringing Power and Knowledge Together: Information Systems Design for Autonomy and Control in Command Work, 2000, ISBN 91-7219796-X.

No 660 Erik Larsson: An Integrated System-Level Design for Testability Methodology, 2000, ISBN 91-7219-890-7.

No 688 Marcus Bjäreland: Model-based Execution Monitoring, 2001, ISBN 91-7373-016-5.

No 689 Joakim Gustafsson: Extending Temporal Action Logic, 2001, ISBN 91-7373-017-3.

No 720 Carl-Johan Petri: Organizational Information Provision - Managing Mandatory and Discretionary Use of Information Technology, 2001, ISBN-91-7373-1269.

No 724 Paul Scerri: Designing Agents for Systems with Adjustable Autonomy, 2001, ISBN 9173732079.

No 725 Tim Heyer: Semantic Inspection of Software Artifacts: From Theory to Practice, 2001, ISBN 91 73732087.

No 726 Pär Carlshamre: A Usability Perspective on Requirements Engineering - From Methodology to Product Development, 2001, ISBN 9173732125.

No 732 Juha Takkinen: From Information Management to Task Management in Electronic Mail, 2002, ISBN 91 73732583.

No 745 Johan Åberg: Live Help Systems: An Approach to Intelligent Help for Web Information Systems, 2002, ISBN 91-7373-311-3.

No 746 Rego Granlund: Monitoring Distributed Teamwork Training, 2002, ISBN 91-7373-312-1.

No 757 Henrik André-Jönsson: Indexing Strategies for Time Series Data, 2002, ISBN 917373-346-6.

No 747 Anneli Hagdahl: Development of IT-supported Interorganisational Collaboration - A Case Study in the Sw edish Public Sector, 2002, ISBN 91-7373-314-8.

No 749 Sofie Pilemalm: Information Technology for NonProfit Organisations - Extended Participatory Design of an Information System for Trade Union Shop Stew ard s, 2002, ISBN 91-7373-318-0.

No 765 Stefan Holmlid: Adapting users: Towards a theory of use quality, 2002, ISBN 91-7373-397-0.

No 771 Magnus Morin: Multimedia Representations of Distributed Tactical Operations, 2002, ISBN 91-7373-4217.

No 772 Pawel Pietrzak: A Type-Based Framework for Locating Errors in Constraint Logic Programs, 2002, ISBN 91-7373-422-5.

No 758 Erik Berglund: Library Communication Among Programmers World wide, 2002, ISBN 91-7373-349-0.

No 774 Choong-ho Yi: Modelling Object-Oriented Dynamic Systems Using a Logic-Based Framew ork, 2002, ISBN 91-7373-424-1.

No 779 Mathias Broxvall: A Study in the Computational Complexity of Temporal Reasoning, 2002, ISBN 917373-440-3.

No 793 Asmus Pandikow: A Generic Principle for Enabling Interoperability of Structured and Object-Oriented Analysis and Design Tools, 2002, ISBN 91-7373-479-9.

No 785 Lars Hult: Publika Informationstjänster. En studie av den Internetbaserade encyklopedins bruksegenskaper, 2003, ISBN 91-7373-461-6.

No 800 Lars Taxén: A Framework for the Coordination of Complex Systems' Development, 2003, ISBN 917373-604-X
No 808 Klas Gäre: Tre perspektiv på förväntningar och förändringar $i$ samband med införande av informationssystem, 2003, ISBN 91-7373-618-X.

No 821 Mikael Kindborg: Concurrent Comics programming of social agents by children, 2003, ISBN 91-7373-651-1.

No 823 Christina Ölvingson: On Development of Information Systems with GIS Functionality in Public Health Informatics: A Requirements Engineering Approach, 2003, ISBN 91-7373-656-2.

No 828 Tobias Ritzau: Memory Efficient Hard Real-Time Garbage Collection, 2003, ISBN 91-7373-666-X.

No 833 Paul Pop: Analysis and Synthesis of Communication-Intensive Heterogeneous Real-Time Systems, 2003, ISBN 91-7373-683-X.

No 852 Johan Moe: Observing the Dynamic Behaviour of Large Distributed Systems to Improve Development and Testing - An Empirical Study in Software Engineering, 2003, ISBN 91-7373-779-8.

No 867 Erik Herzog: An Approach to Systems Engineering Tool Data Representation and Exchange, 2004, ISBN 91-7373-929-4.

No 872 Aseel Berglund: Augmenting the Remote Control: Studies in Complex Information Navigation for Digital TV, 2004, ISBN 91-7373-940-5.

No 869 Jo Skåmedal: Telecommuting's Implications on Travel and Travel Patterns, 2004, ISBN 91-7373-935-9.

No 870 Linda Askenäs: The Roles of IT - Studies of Organising when Implementing and Using Enterprise Systems, 2004, ISBN 91-7373-936-7.

No 874 Annika Flycht-Eriksson: Design and Use of Ontologies in Information-Providing Dialogue Systems, 2004, ISBN 91-7373-947-2.

No 873 Peter Bunus: Debugging Techniques for EquationBased Languages, 2004, ISBN 91-7373-941-3.

No 876 Jonas Mellin: Resource-Predictable and Efficient Monitoring of Events, 2004, ISBN 91-7373-956-1.

No 883 Magnus Bång: Computing at the Speed of Paper: Ubiquitous Computing Environments for Healthcare Professionals, 2004, ISBN 91-7373-971-5

No 882 Robert Eklund: Disfluency in Swedish humanhuman and human-machine travel booking dialogues, 2004, ISBN 91-7373-966-9.

No 887 Anders Lindström: English and other Foreign Linguistic Elements in Spoken Swedish. Studies of Productive Processes and their Modelling using Finite-State Tools, 2004, ISBN 91-7373-981-2.

No 889 Zhiping Wang: Capacity-Constrained Production-inventory systems - Modelling and Analysis in both a traditional and an e-business context, 2004, ISBN 9185295-08-6.

No 893 Pernilla Qvarfordt: Eyes on Multimodal Interaction, 2004, ISBN 91-85295-30-2.

No 910 Magnus Kald: In the Borderland between Strategy and Management Control - Theoretical Framework and Empirical Evidence, 2004, ISBN 91-85295-82-5.

No 918 Jonas Lundberg: Shaping Electronic News: Genre Perspectives on Interaction Design, 2004, ISBN 9185297-14-3.

No 900 Mattias Arvola: Shades of use: The dynamics of interaction design for sociable use, 2004, ISBN 9185295-42-6.

No 920 Luis Alejandro Cortés: Verification and Scheduling Techniques for Real-Time Embedded Systems, 2004, ISBN 91-85297-21-6.

No 929 Diana Szentivanyi: Performance Studies of FaultTolerant Middleware, 2005, ISBN 91-85297-58-5. 
No 933 Mikael Cäker: Management Accounting as Constructing and Opposing Customer Focus: Three Case Studies on Management Accounting and Customer Relations, 2005, ISBN 91-85297-64-X.

No 937 Jonas Kvarnström: TALplanner and Other Extensions to Temporal Action Logic, 2005, ISBN 9185297-75-5.

No 938 Bourhane Kadmiry: Fuzzy Gain-Scheduled Visual Servoing for Unmanned Helicopter, 2005, ISBN 9185297-76-3.

No 945 Gert Jervan: Hybrid Built-In Self-Test and Test Generation Techniques for Digital Systems, 2005, ISBN : 91-85297-97-6.

No 946 Anders Arpteg: Intelligent Semi-Structured Information Extraction, 2005, ISBN 91-85297-98-4.

No 947 Ola Angelsmark: Constructing Algorithms for Constraint Satisfaction and Related Problems - Methods and Applications, 2005, ISBN 91-85297-99-2.

No 963 Calin Curescu: Utility-based Optimisation of Resource Allocation for Wireless Networks, 2005, ISBN 91-85457-07-8.

No 972 Björn Johansson: Joint Control in Dynamic Situations, 2005, ISBN 91-85457-31-0.

No 974 Dan Lawesson: An Approach to Diagnosability Analysis for Interacting Finite State Systems, 2005, ISBN 91-85457-39-6.

No 979 Claudiu Duma: Security and Trust Mechanisms for Groups in Distributed Services, 2005, ISBN 91-8545754-X.

No 983 Sorin Manolache: Analysis and Optimisation of Real-Time Systems with Stochastic Behaviour, 2005, ISBN 91-85457-60-4.

No 986 Yuxiao Zhao: Standards-Based Application Integration for Business-to-Business Communications, 2005, ISBN 91-85457-66-3.

No 1004 Patrik Haslum: Admissible Heuristics for Automated Planning, 2006, ISBN 91-85497-28-2.

No 1005 Aleksandra Tešanovic: Developing Reusable and Reconfigurable Real-Time Software using Aspects and Components, 2006, ISBN 91-85497-29-0.

No 1008 David Dinka: Role, Identity and Work: Extending the design and development agenda, 2006, ISBN 91 85497-42-8

No 1009 Iakov Nakhimovski: Contributions to the Modeling and Simulation of Mechanical Systems with Detailed Contact Analysis, 2006, ISBN 91-85497-43-X

No 1013 Wilhelm Dahllöf: Exact Algorithms for Exact Satisfiability Problems, 2006, ISBN 91-85523-97-6.

No 1016 Levon Saldamli: PDEModelica - A High-Level Language for Modeling with Partial Differential Equations, 2006, ISBN 91-85523-84-4.

No 1017 Daniel Karlsson: Verification of Component-based Embedded System Designs, 2006, ISBN 91-85523-79-8

No 1018 Ioan Chisalita: Communication and Networking Techniques for Traffic Safety Systems, 2006, ISBN 9185523-77-1

No 1019 Tarja Susi: The Puzzle of Social Activity - The Significance of Tools in Cognition and Cooperation, 2006, ISBN 91-85523-71-2.

No 1021 Andrzej Bednarski: Integrated Optimal Code Generation for Digital Signal Processors, 2006, ISBN 9185523-69-0.

No 1022 Peter Aronsson: Automatic Parallelization of Equation-Based Simulation Programs, 2006, ISBN 9185523-68-2.
No 1030 Robert Nilsson: A Mutation-based Framework for Automated Testing of Timeliness, 2006, ISBN 9185523-35-6.

No 1034 Jon Edvardsson: Techniques for Automatic Generation of Tests from Programs and Specifications, 2006, ISBN 91-85523-31-3.

No 1035 Vaida Jakoniene: Integration of Biological Data, 2006, ISBN 91-85523-28-3.

No 1045 Genevieve Gorrell: Generalized Hebbian Algorithms for Dimensionality Reduction in Natural Language Processing, 2006, ISBN 91-85643-88-2.

No 1051 Yu-Hsing Huang: Having a New Pair of Glasses Applying Systemic Accident Models on Road Safety, 2006, ISBN 91-85643-64-5.

No 1054 Åsa Hedenskog: Perceive those things which cannot be seen - A Cognitive Systems Engineering perspective on requirements management, 2006, ISBN 91-85643-57-2.

No 1061 Cécile Åberg: An Evaluation Platform for Semantic Web Technology, 2007, ISBN 91-85643-31-9.

No 1073 Mats Grindal: Handling Combinatorial Explosion in Software Testing, 2007, ISBN 978-91-85715-74-9.

No 1075 Almut Herzog: Usable Security Policies for Runtime Environments, 2007, ISBN 978-91-85715-65-7.

No 1079 Magnus Wahlström: Algorithms, measures, and upper bounds for Satisfiability and related problems, 2007, ISBN 978-91-85715-55-8

No 1083 Jesper Andersson: Dynamic Software Architectures, 2007, ISBN 978-91-85715-46-6.

No 1086 Ulf Johansson: Obtaining Accurate and Comprehensible Data Mining Models - An Evolutionary Approach, 2007, ISBN 978-91-85715-34-3.

No 1089 Traian Pop: Analysis and Optimisation of Distributed Embedded Systems with Heterogeneous Scheduling Policies, 2007, ISBN 978-91-85715-27-5.

No 1091 Gustav Nordh: Complexity Dichotomies for CSPrelated Problems, 2007, ISBN 978-91-85715-20-6.

No 1106 Per Ola Kristensson: Discrete and Continuous Shape Writing for Text Entry and Control, 2007, ISBN 97891-85831-77-7.

No 1110 He Tan: Aligning Biomedical Ontologies, 2007, ISBN 978-91-85831-56-2.

No 1112 Jessica Lindblom: Minding the body - Interacting socially through embodied action, 2007, ISBN 978-9185831-48-7.

No 1113 Pontus Wärnestål: Dialogue Behavior Management in Conversational Recommender Systems, 2007, ISBN 978-91-85831-47-0.

No 1120 Thomas Gustafsson: Management of Real-Time Data Consistency and Transient Overloads in Embedded Systems, 2007, ISBN 978-91-85831-33-3.

No 1127 Alexandru Andrei: Energy Efficient and Predictable Design of Real-time Embedded Systems, 2007, ISBN 978-91-85831-06-7.

No 1139 Per Wikberg: Eliciting Knowledge from Experts in Modeling of Complex Systems: Managing Variation and Interactions, 2007, ISBN 978-91-85895-66-3.

No 1143 Mehdi Amirijoo: QoS Control of Real-Time Data Services under Uncertain Workload, 2007, ISBN 97891-85895-49-6.

No 1150 Sanny Syberfeldt: Optimistic Replication with Forward Conflict Resolution in Distributed Real-Time Databases, 2007, ISBN 978-91-85895-27-4

No 1155 Beatrice Alenljung: Envisioning a Future Decision Support System for Requirements Engineering - A Holistic and Human-centred Perspective, 2008, ISBN 978-91-85895-11-3 
No 1156 Artur Wilk: Types for XML with Application to Xcerpt, 2008, ISBN 978-91-85895-08-3.

No 1183 Adrian Pop: Integrated Model-Driven Development Environments for Equation-Based Object-Oriented Languages, 2008, ISBN 978-91-7393-895-2.

No 1185 Jörgen Skågeby: Gifting Technologies Ethnographic Studies of End-users and Social Media Sharing, 2008, ISBN 978-91-7393-892-1.

No 1187 Imad-Eldin Ali Abugessaisa: Analytical tools and information-sharing methods supporting road safety organizations, 2008, ISBN 978-91-7393-887-7.

No 1204 H. Joe Steinhauer: A Representation Scheme for Description and Reconstruction of Object Configurations Based on Qualitative Relations, 2008, ISBN 978-91-7393-823-5.

No 1222 Anders Larsson: Test Optimization for Core-based System-on-Chip, 2008, ISBN 978-91-7393-768-9.

No 1238 Andreas Borg: Processes and Models for Capacity Requirements in Telecommunication Systems, 2009, ISBN 978-91-7393-700-9.

No 1240 Fredrik Heintz: DyKnow: A Stream-Based Knowledge Processing Middleware Framework, 2009, ISBN 978-91-7393-696-5.

No 1241 Birgitta Lindström: Testability of Dynamic RealTime System s, 2009, ISBN 978-91-7393-695-8.

No 1244 Eva Blomqvist: Semi-automatic Ontology Construction based on Patterns, 2009, ISBN 978-91-7393-683-5.

No 1249 Rogier Woltjer: Functional Modeling of Constraint Management in Aviation Safety and Command and Control, 2009, ISBN 978-91-7393-659-0.

No 1260 Gianpaolo Conte: Vision-Based Localization and Guidance for Unmanned Aerial Vehicles, 2009, ISBN 978-91-7393-603-3.

No 1262 AnnMarie Ericsson: Enabling Tool Support for Formal Analysis of ECA Rules, 2009, ISBN 978-91-7393598-2.

No 1266 Jiri Trnka: Exploring Tactical Command and Control: A Role-Playing Simulation Approach, 2009, ISBN 978-91-7393-571-5.

No 1268 Bahlol Rahimi: Supporting Collaborative Work through ICT - How End-users Think of and Adopt Integrated Health Information Systems, 2009, ISBN 978-91-7393-550-0.

No 1274 Fredrik Kuivinen: Algorithms and Hardness Results for Some Valued CSPs, 2009, ISBN 978-91-7393-525-8.

No 1281 Gunnar Mathiason: Virtual Full Replication for Scalable Distributed Real-Time Databases, 2009, ISBN 978-91-7393-503-6.

No 1290 Viacheslav Izosimov: Scheduling and Optimization of Fault-Tolerant Distributed Embedded Systems, 2009, ISBN 978-91-7393-482-4.

No 1294 Johan Thapper: Aspects of a Constraint Optimisation Problem, 2010, ISBN 978-91-7393-464-0.

No 1306 Susanna Nilsson: Augmentation in the Wild: User Centered Development and Evaluation of Augmented Reality Applications, 2010, ISBN 978-917393-416-9.

No 1313 Christer Thörn: On the Quality of Feature Models, 2010, ISBN 978-91-7393-394-0.

No 1321 Zhiyuan He: Temperature Aware and DefectProbability Driven Test Scheduling for System-onChip, 2010, ISBN 978-91-7393-378-0.

No 1333 David Broman: Meta-Languages and Semantics for Equation-Based Modeling and Simulation, 2010, ISBN 978-91-7393-335-3.

No 1337 Alexander Siemers: Contributions to Modelling and Visualisation of Multibody Systems Simulations with
Detailed Contact Analysis, 2010, ISBN 978-91-7393317-9.

No 1354 Mikael Asplund: Disconnected Discoveries: Availability Studies in Partitioned Networks, 2010, ISBN 978-91-7393-278-3.

No 1359 Jana Rambusch: Mind Games Extended: Understanding Gameplay as Situated Activity, 2010, ISBN 978-91-7393-252-3.

No 1373 Sonia Sangari: Head Movement Correlates to Focus Assignment in Swedish,2011,ISBN 978-91-7393-154-0.

No 1374 Jan-Erik Källhammer: Using False Alarms when Developing Automotive Active Safety Systems, 2011, ISBN 978-91-7393-153-3.

No 1375 Mattias Eriksson: Integrated Code Generation, 2011, ISBN 978-91-7393-147-2.

No 1381 Ola Leifler: Affordances and Constraints of Intelligent Decision Support for Military Command and Control - Three Case Studies of Support Systems, 2011, ISBN 978-91-7393-133-5.

No 1386 Soheil Samii: Quality-Driven Synthesis and Optimization of Embedded Control Systems, 2011, ISBN 978-91-7393-102-1.

No 1419 Erik Kuiper: Geographic Routing in Intermittentlyconnected Mobile Ad Hoc Networks: Algorithms and Performance Models, 2012, ISBN 978-91-7519981-8.

No 1451 Sara Stymne: Text Harmonization Strategies for Phrase-Based Statistical Machine Translation, 2012, ISBN 978-91-7519-887-3.

No 1455 Alberto Montebelli: Modeling the Role of Energy Management in Embodied Cognition, 2012, ISBN 978-91-7519-882-8

No 1465 Mohammad Saifullah: Biologically-Based Interactive Neural Network Models for Visual Attention and Object Recognition, 2012, ISBN 978-91-7519-838-5.

No 1490 Tomas Bengtsson: Testing and Logic Optimization Techniques for Systems on Chip, 2012, ISBN 978-917519-742-5.

No 1481 David Byers: Improving Software Security by Preventing Known Vulnerabilities, 2012, ISBN 97891-7519-784-5.

No 1496 Tommy Färnqvist: Exploiting Structure in CSPrelated Problems, 2013, ISBN 978-91-7519-711-1.

No 1503 John Wilander: Contributions to Specification, Implementation, and Execution of Secure Software, 2013, ISBN 978-91-7519-681-7.

No 1506 Magnus Ingmarsson: Creating and Enabling the Useful Service Discovery Experience, 2013, ISBN 97891-7519-662-6.

No 1547 Wladimir Schamai: Model-Based Verification of Dynamic System Behavior against Requirements: Method, Language, and Tool, 2013, ISBN 978-917519-505-6.

No 1551 Henrik Svensson: Simulations, 2013, ISBN 978-917519-491-2.

No 1559 Sergiu Rafiliu: Stability of Adaptive Distributed Real-Time Systems with Dynamic Resource Management, 2013, ISBN 978-91-7519-471-4.

No 1581 Usman Dastgeer: Performance-aware Component Composition for GPU-based Systems, 2014, ISBN 978-91-7519-383-0

No 1602 Cai Li: Reinforcement Learning of Locomotion based on Central Pattern Generators, 2014, ISBN 978-917519-313-7.

No 1652 Roland Samlaus: An Integrated Development Environment with Enhanced Domain-Specific 
Interactive Model Validation, 2015, ISBN 978-91 7519-090-7.

No 1663 Hannes Uppman: On Some Combinatorial Optimization Problems: Algorithms and Complexity, 2015, ISBN 978-91-7519-072-3.

Linköping Studies in Arts and Science

No 504 Ing-Marie Jonsson: Social and Emotional Characteristics of Speech-based In-Vehicle Information Systems: Impact on Attitude and Driving Behaviour, 2009, ISBN 978-91-7393-478-7.

No 586 Fabian Segelström: Stakeholder Engagement for Service Design: How service designers identify and communicate insights, 2013, ISBN 978-91-7519-554-4.

No 618 Johan Blomkvist: Representing Future Situations of Service: Prototyping in Service Design, 2014, ISBN 978-91-7519-343-4.

No 620 Marcus Mast: Human-Robot Interaction for SemiAutonomous Assistive Robots, 2014, ISBN 978-917519-319-9.

\section{Linköping Studies in Statistics}

No 9 Davood Shahsavani: Computer Experiments Designed to Explore and Approximate Complex Deterministic Models, 2008, ISBN 978-91-7393-976-8.

No 10 Karl Wahlin: Roadmap for Trend Detection and Assessment of Data Quality, 2008, ISBN 978-91-7393$792-4$

No 11 Oleg Sysoev: Monotonic regression for large multivariate datasets, 2010, ISBN 978-91-7393-412-1.

No 13 Agné Burauskaite-Harju: Characterizing Temporal Change and Inter-Site Correlations in Daily and Subdaily Precipitation Extremes, 2011, ISBN 978-91-7393$110-6$.

\section{Linköping Studies in Information Science}

No 1 Karin Axelsson: Metodisk systemstrukturering- att skapa samstämmighet mellan informationssystemarkitektur och verksamhet, 1998. ISBN-9172-19-296-8.

No 2 Stefan Cronholm: Metodverktyg och användbarhet en studie av datorstödd metodbaserad systemutveckling, 1998, ISBN-9172-19-299-2.

No 3 Anders Avdic: Användare och utvecklare - om anveckling med kalkylprogram, 1999. ISBN-91-7219606-8.

No 4 Owen Eriksson: Kommunikationskvalitet hos informationssystem och affärsprocesser, 2000, ISBN 917219-811-7.

No 5 Mikael Lind: Från system till process - kriterier för processbestämning vid verksamhetsanalys, 2001, ISBN 91-7373-067-X

No 6 Ulf Melin: Koordination och informationssystem företag och nätverk, 2002, ISBN 91-7373-278-8

No 7 Pär J. Ågerfalk: Information Systems Actability - Understanding Information Technology as a Tool for Business Action and Communication, 2003, ISBN 917373-628-7.

No 8 Ulf Seigerroth: Att förstå och förändra systemutvecklingsverksamheter - en taxonomi för metautveckling, 2003, ISBN91-7373-736-4.

No 9 Karin Hedström: Spår av datoriseringens värden Effekter av IT i äldreomsorg, 2004, ISBN 91-7373-9634.

No 10 Ewa Braf: Knowledge Demanded for Action Studies on Knowledge Mediation in Organisations, 2004, ISBN 91-85295-47-7.
No 11 Fredrik Karlsson: Method Configuration method and computerized tool support, 2005, ISBN 91-8529748-8.

No 12 Malin Nordström: Styrbar systemförvaltning - At organisera systemförvaltningsverksamhet med hjälp av effektiva förvaltningsobjekt, 2005, ISBN 91-8529760-7.

No 13 Stefan Holgersson: Yrke: POLIS - Yrkeskunskap, motivation, IT-system och andra förutsättningar för polisarbete, 2005, ISBN 91-85299-43-X.

No 14 Benneth Christiansson, Marie-Therese Christiansson: Mötet mellan process och komponent - mot ett ramverk för en verksamhetsnära kravspecifikation vid anskaffning av komponentbaserade informationssystem, 2006, ISBN 91-85643$22-\mathrm{X}$ 